\title{
CUANDO EL PERIURBANO COBRA VIDA PROPIA. LA MOVILIDAD DIARIA Y RESIDENCIAL COMO CLAVES PARA CARACTERIZAR EL ÁREA METROPOLITANA DE SANTANDER
}

\author{
Olga De Cos Guerra \\ Universidad de Cantabria \\ olga.decos@unican.es \\ ORCID ID: https://orcid.org/0000-0002-2245-5378
}

Recibido: 14/03/2021; Aceptado: 29/10/2021; Publicado: 17/01/2022

Cómo citar este artículo/Citation: De Cos Guerra, Olga (2021) Cuando el periurbano cobra vida propia. La movilidad diaria y residencial como claves para caracterizar el área metropolitana de Santander. Estudios Geográficos, 82 (291), e082. https://doi. org/10.3989/estgeogr.202193.093

RESUMEN: Este trabajo analiza la configuración actual del área metropolitana de Santander tomando como punto de partida el área urbana funcional reconocida con criterios europeos. Para ello, se aplican métodos de análisis SIG y se integran reveladoras fuentes, como las coberturas de Copernicus, las edificaciones y la población por cuadrícula de Global Human Settlement y fuentes estadísticas sobre movilidad residencial y diaria. Este enfoque permite no sólo analizar la organización interna del área funcional, sino también cuantificar en clave de sostenibilidad los principales procesos que en ella acontecen: artificialización, dispersión, discontinuidad y un crecimiento demográfico que se manifiesta en más zonas ocupadas con menor densidad. Los resultados permiten poner en valor los estudios geográficos sobre ocupación del suelo y movilidad en las áreas urbanas funcionales, a la vez que posibilitan una reflexión sobre la función de la escala metropolitana en el marco de la Agenda Urbana. Estamos ante el reto de la sostenibilidad urbana y de la preservación de una infraestructura verde que actúe como garantía de calidad de vida frente a una expansión urbana tendencial, fragmentadora y altamente consumidora de suelo. Por último, la utilidad de las fuentes citadas - y su disponibilidad para los distintos países europeos - posibilitaría analizar la cuestión metropolitana con un enfoque similar en otros sistemas españoles y, en su caso, europeos.

PALABRAS CLAVE: áreas urbanas funcionales; dispersión espacial; artificialización; ex pansión urbana; variaciones residenciales; Copernicus; Agenda Urbana.

\section{When periurban areas come to life. Commuting and residential variations, keys to characterize the metropolitan area of Santander.}

ABSTRACT: This study analyses the current configuration of the metropolitan area of Santander, considering the functional urban area based on European criteria. For that purpose, GIS analyst methods are applied, and many sources are integrated, such as: coverages from Copernicus, buildings, and inhabitants per grid from Global Human Settlement and sources about commuting and residential variations. This approach is necessary not only to analyse the internal organization of the functional urban area, but also to quantify main processes from a sustainable perspective: artificialization, dispersion, discontinuity, and population growth that show many new residential areas with lower density. The research results are important to emphasize geographic studies about land use and mobility in functional urban areas. Furthermore, results enable to reflect about the importance of metropolitan scale to address the urban sustainability challenge in the framework of Urban Agenda. Regarding to this, the green infrastructure may preserve and guarantee the quality of life against the unsustainable urban sprawl. Finally, this model could be applied to other case studies in Spain or even in other European cities, due to the use of European sources. KEY WORDS: functional u rban areas; spatial dispersion; artificialization; urban spraw l; residential variati ons; Coperni cus; Urban Agenda. 


\section{INTRODUCCIÓN}

Las áreas metropolitanas se presentan como una realidad incuestionable desde el punto de vista territorial, demográfico y funcional. Las sólidas investigaciones desarrolladas desde distintas disciplinas, y muy singularmente desde la Geografía, así lo evidencian. Sin embargo, en España estos discursos categóricamente defendidos a distintos niveles y escalas, transferidos ante gobiernos autonómicos por parte de consolidados equipos expertos en la materia, llevan décadas enfrentándose y perdiendo la pugna para su reconocimiento institucional y administrativo, a la par que político y social. Las áreas metropolitanas se han convertido, así, en realidades "invisibles desde la perspectiva político-institucional" (Hildenbrand, 2017, p. 25), o más exactamente invisibilizadas, originando una situación que contrasta con el tratamiento dado a la cuestión metropolitana en algunos países europeos como Alemania, Francia o Reino Unido, entre otros.

La inacción administrativa o, en su caso, el posible negacionismo ante lo metropolitano, no van a cambiar la realidad, no van a frenar el proceso de metropolización, no van a evitar el consumo difuso de suelo a través de un crecimiento discontinuo convertido en la peor metáfora territorial de la expresión "stepping stones" (Pesci, 2018, p. 21) que descompone el paisaje metropolitano, reduciendo espacios de dominancia natural, superficies agrarias y fragmentando hábitats (Feria y Santiago, 2019). Además de la indudable afección al medio natural y a la biodiversidad, este modelo de crecimiento discontinuo favorecido por la disminución de la distancia percibida, también condiciona el bienestar y la calidad de vida de la población residente. De hecho, conlleva un aumento de las emisiones por el incremento de los desplazamientos, generando mayores niveles de contaminación que terminan afectando a la población, a sus condiciones de salud y a su relación con el medio (Guastella, Oueslati y Pareglio, 2019).

Frente a este modelo de "ciudad extensa" (Olazabal y Bellet, 2016), el control de los procesos de expansión y la apuesta por la densificación se postulan en algunos estudios como una vía de garantía de sostenibilidad. Ello permitiría asegurar el adecuado tratamiento de los espacios verdes urbanos con perspectiva multiescalar, no solo en los cómputos generales de los planeamientos municipales, sino desde los barrios, desde los espacios vividos de la población, desde la microescala hasta la comarca y la región. Este planteamiento $-\mathrm{y}$ la dificultad de hacerlo realidad frente al modelo de expansión urbana tendencial- ha hecho que algunos autores lleguen a considerarlo como el reto de la ciudad compacta verde con áreas verdes multifuncionales (Artmann, Inostroza y Fan, 2019). Este enfoque contrapone el principio que imperó décadas atrás, cuando en el cambio de siglo lo verde, y su beneficio sobre la salud de los residentes, eran aspectos asociados a un periurbano "idílico" de baja densidad que, por otro lado, ha conllevado un alto consumo de suelo. Esto demuestra que siguen vigentes las líneas de investigación sobre los beneficios de la compacidad en torno al crecimiento urbano - ya apuntado en los 90 por la Comisión de las Comunidades Europeas con el Libro verde sobre el crecimiento urbano (CEC, 1990)-. Sin embargo, a pesar de que en el referido documento ya se recogían buena parte de los asuntos que hoy en día se asocian a la expansión urbana, es preciso señalar que en su mayoría los grandes temas se encuentran aún pendientes de resolver. Puede interpretarse que el Libro verde presentaba un panorama de la periferia que podría tildarse de excesivamente negativo en lo que se refiere a contenido social y condiciones securitarias; sin embargo, este documento cuenta con el reconocimiento de aportar una buena base y orientación de lo que serían los grandes retos del modelo de crecimiento urbano en las décadas siguientes. Hoy en día, esas preocupaciones -en parte premonitorias - constituyen un prisma indispensable para afrontar los retos de sostenibilidad global frente a las previsiones de crecimiento urbano estimadas por Naciones Unidas (2018) para el horizonte 2030 , donde un $60 \%$ de la población mundial residiría en áreas urbanas, y una de cada tres personas lo haría en sistemas que superan el millón de habitantes.

En la misma línea de investigaciones que apuestan por los beneficios de la compactación y la densificación urbana, autores como Bibri, Krogstie y Kärrholm (2020) - tras analizar el caso de dos ciudades de la costa oeste de Suecia- concluyen que Gotemburgo y Helsingborg constituyen casos de éxito en clave de políticas globales y locales de planeamiento urbano. Son ejemplos de ciudades compactas, exponentes de integración medioambiental, desarrollo económico y justicia social. De hecho, los autores se basan en el planteamiento de los beneficios multidimensionales de la densidad en áreas urbanas: dotación de servicios de cercanía, fomento del transporte público y establecimiento de rutas para caminar e ir en bicicleta, variedad de actividades económicas y servicios, mayor seguridad, fomento del estilo de vida urbano y mejora e incremento de parques y zonas de juego, etc. (Bibri et al., 2020). 
Además de este marco conceptual introductorio, es preciso señalar que la temática abordada en este artículo ha sido ampliamente tratada como tema de investigación, dada la importancia de los procesos acontecidos en entornos periurbanos. Así, las áreas de expansión urbana centran la atención de organismos e investigaciones con la finalidad de descifrar las pautas de la expansión urbana discontinua a nivel europeo. Más específicamente, se identifica un interés especial por afrontar los retos que los modelos de expansión urbana suponen no solo en la actualidad, sino también en el futuro. En este sentido, la identificación de áreas urbanas funcionales a nivel europeo (Functional Urban Areas, FUA en su acrónimo inglés) y la generación de fuentes de información geográfica y estadística para estos entornos, ha posibilitado el desarrollo de estudios que llegan a plantear el contradictorio modelo de la expansión urbana en Europa. El patrón espacial resultante, que se materializa en la disminución de la densidad y el aumento de la dispersión, con diferencias y matices entre casos, parece estar institucionalmente permitido, e incluso fomentado, por un desacoplamiento entre las políticas de desarrollo urbano y las tendencias demográficas (Guastella et al., 2019).

En ese sentido, las periferias urbanas dejan de verse como meros espacios dependientes de las dinámicas centrales, convirtiéndose en áreas que atraen, incluso, la atención de la política urbana europea en la llamada fase de "europeización urbana", sustentada en un enfoque urbano sostenible integrado (GonzálezMedina, Huete y Merino, 2016, p. 89) y materializada en un claro reto para España: que la Agenda Urbana, a pesar de no ser vinculante, se convierta realmente en una política urbana nacional (De la Cruz, 2019).

La Agenda Urbana supera el tratamiento sectorial de los procesos urbano-metropolitanos, al menos en lo que a enfoque temático se refiere, y se estructura en torno a ejes fundamentales, como el "uso sostenible del suelo", la "adaptación climática", la "movilidad urbana" o la "vivienda", entre otros (González-Medina et al., 2016, p. 90), que establecen la hoja de ruta a seguir en el contexto de los Objetivos de Desarrollo Sostenible de 2015 (ODS). Ahora, el camino que queda por recorrer estará marcado por la prioridad de superar también las visiones parciales desde el punto de vista administrativo-territorial, que tan sujetas - casi atrapadas - están por la constreñida gestión municipal. La realidad metropolitana hace décadas que ha rebasado el territorio de las estructuras administrativas municipales en las que se apoya el diseño y gestión de las figuras de planeamiento. Además, hay interesantes estudios que demuestran la obsolescencia de buena parte de las figuras de planeamiento en España. Según Lobato-Becerra (2020) más de dos tercios de los municipios no cuentan con planes generales de ordenación urbana, y los que tienen esta figura, en más de la mitad de los casos presentan periodos de vigencia superiores a una década. Ello, tal como señala Lobato-Becerra (2020), deja parte de los planes en marcos legislativos previos a las leyes autonómicas vigentes en la materia.

Incluso, algunos estudios de enfoque económico demuestran otras facetas de la fragmentación municipal en relación con la gestión de la expansión urbana. Así, del mismo modo que es competencia municipal la elaboración del planeamiento aplicable en su territorio, también lo es la dotación de servicios a la población residente. Con ello, según Fernández-Milán y Creutzig (2016), un modelo de expansión urbana basado en una política municipal permisiva lleva asociado un mayor volumen de deuda en la administración local, a la vez que deriva en un modelo urbano poco sostenible.

Con este telón de fondo, la presente investigación se centra en el análisis del área metropolitana de Santander, donde la descentralización y la segregación funcional iniciada en la década de los noventa han dado paso a un destacado proceso de artificialización del suelo. Todo ello, en un momento estratégico, al iniciar el Ayuntamiento de Santander en 2020 la elaboración del nuevo Plan General de Ordenación Urbana.

Este hecho cobra especial relevancia si se tiene en cuenta que, en el momento de realización del presente estudio, el plan vigente del municipio capital de la Comunidad Autónoma de Cantabria es del año 1997, previo por tanto a la Ley 2/2001 de Ordenación Territorial y Régimen Urbanístico del Suelo de Cantabria. La obsolescencia de este planeamiento municipal no es fruto de la dejadez o de la ausencia de intentos de actualización. De hecho, en el periodo que media entre el plan de 1997 y 2021, hubo un plan intermedio - aprobado por la Comisión Regional de Ordenación del Territorio y Urbanismo (CROTU) en septiembre de 2012-, pero en octubre de 2016 fue anulado por la Sala Contencioso Administrativa del Tribunal Supremo, lo que conllevó el retorno al último plan vigente (1997); por eso, su duración abarca un periodo que ya se acerca a los 25 años.

Tal como se apuntaba, en el momento de realización del presente estudio (2020-2021), el Ayuntamiento de Santander ha iniciado los trabajos del futuro plan 
general, con el propósito de que sea aprobado antes del final de legislatura en 2023. Entre los pasos dados, destaca la iniciativa del ayuntamiento para recopilar estudios académicos bajo la denominación "Sabiduría de la ciudad". Parte de estos estudios se materializaron en el proyecto con la Universidad de Cantabria "Diagnosis urbanística y geodemográfica de Santander" (2021), donde se contemplaba un apartado relativo al área metropolitana de Santander. Por otro lado, el Ayuntamiento de Santander desarrolló, entre los meses de julio y septiembre de 2020, la fase 0 de consulta previa ciudadana bajo el lema "Santander lo piensas tú", con el objetivo de generar un conocimiento actual e integrado de la ciudad, así como debate y opinión, a través de una llamada a la participación en distintos formatos presenciales y telemáticos. En esta fase el concepto de área metropolitana aparecía solo tímidamente señalado; si bien, sería de interés propiciar el debate ciudadano al respecto, lo que podría incluso servir como experiencia de sensibilización preparatoria para el planteamiento de un futuro modelo de gobernanza metropolitana. Ese escenario de perspectiva supramunicipal podría iniciarse gradualmente con colaboraciones voluntarias bajo modelos de "soft governance" (Hildenbrand, 2017, p. 25) hasta que se pueda alcanzar el marco óptimo y deseable de planes de ordenación del territorio metropolitanos o, en su caso, "instrumentos de ordenación subregionales con carácter vinculante" (Selva-Royo, 2020, p. 221).

Parece, por tanto, el momento oportuno para desarrollar este estudio con el objetivo de analizar el área metropolitana de Santander, constatada realidad territorial, demográfica y funcional, integrada inicialmente por nueve municipios, según un modelo multicriterio diseñado específicamente hace quince años (De Cos, 2005). Esa delimitación supuso una aportación de interés en la región y fue reconocida por el Gobierno de Cantabria con el I Premio del Centro de Estudios de la Administración Regional de Cantabria (CEARC). Además, desde un punto de vista disciplinar, cuenta con interés por ser una delimitación integradora de múltiples variables en temáticas diversas (intensidad de ocupación del suelo, accesibilidad y comunicación por transporte público, perfiles económicos, etc.).

Si bien, en el momento actual, es necesario considerar las nuevas fuentes de movilidad (diaria y residencial), de coberturas del suelo y de grado de urbanización para modelizar su configuración en un nuevo marco europeo y nacional (el de la Agenda Urbana), con los Objetivos de Desarrollo Sostenible como fondo y en la coyuntura especial del planteamiento de una nueva figura de planeamiento en el municipio de Santander.

En ese sentido, contamos con destacados estudios a nivel nacional que aproximan áreas metropolitanas y funcionales, o de movilidad, de dimensiones y formas diversas, que cuentan con interés variable en función de la escala de análisis, basados en depuradas metodologías de las que derivan delimitaciones expresivas a nivel nacional (Feria y Martínez, 2016). En esa línea, algunos estudios recientes reafirman la existencia de una realidad supramunicipal que se manifiesta en el área urbana funcional (FUA) de Santander, incluida en la tipología de áreas metropolitanas estándar que, con un rango de población de 300.000 a 800.000 habitantes, representa un área consolidada con una estructura basada en una ciudad central que se suburbaniza en los municipios del entorno (Feria, 2020). Sobre esta base, y con un cambio de escala de análisis - de nacional en el citado trabajo, a regional en este estudio- se pretende profundizar en el comportamiento de este ámbito en relación a la ocupación del suelo, a las variaciones residenciales y la movilidad diaria, para finalmente plantear una reflexión sobre el alcance de la expresión espacial del área metropolitana de Santander, quince años después de su primera delimitación. Un caso de estudio que -como tantos otros sistemas españoles - nunca fueron administrativamente reconocidos. En este momento, tomar como punto de referencia el área urbana funcional aporta interesantes oportunidades en este estudio. Por un lado, permite acceder a fuentes específicas de coberturas con tipologías detalladas para los recintos de las áreas funcionales, que no se tendrían si se optara por delimitaciones propias de otros estudios; además, al consistir las áreas urbanas funcionales en delimitaciones disponibles a nivel europeo, según los criterios de Dijkstra y Poelman (2012), su uso va más allá de un estudio de caso, lo que posibilitaría la comparación de distintas áreas urbanas funcionales con el enfoque y método propuesto.

Con ello, al analizar el área de Santander con las dos delimitaciones de partida (el área metropolitana de nueve municipios y área urbana funcional de veintiuno), se plantea un objetivo adicional, cual es comprobar los matices territoriales del concepto de área urbana funcional frente a área metropolitana, sobre el estudio de caso del área metropolitana de Santander, pero con fuentes y métodos aplicables a otras áreas españolas o, en su caso, europeas.

Si anteriormente se refería en esta introducción al reto de la ciudad compacta verde como modelo urbano 
sostenible y saludable, este estudio también nos permite reflexionar sobre el reto que ello supone para las figuras de planeamiento municipal. Estos instrumentos son conductores y reguladores del modelo de expansión urbana por el que se va a optar, en cuanto que expansión y dispersión discontinua no son sinónimos, ni tienen por qué ir unidos (Artmann et al., 2019). Y es que algunos estudios demuestran la fragilidad de la gobernanza urbana ante la complejidad que ha tomado el modelo de crecimiento difuso y disperso. Esto provoca que temas relevantes pendientes, como el cambio climático, la pérdida de biodiversidad o, incluso, cuestiones de salud pública, se vean afectados por la existencia de unas estructuras administrativas que gestionan con pautas territoriales sesgadas por delimitaciones y fronteras desde la administración local, a escalas que se ven desbordadas por la realidad urbana que pretenden regular (Frank, Spyra y Fürst, 2017). Así, retomando la reflexión de Feria (2020, p. 39) sobre la "ausencia de una sola fórmula universalmente válida para todas las áreas metropolitanas", el planteamiento de modelos de gobernanza metropolitana adaptados a las particularidades de cada caso hace necesario que los estudios geográficos sigan avanzando y profundizando en la identificación, delimitación y caracterización de las distintas áreas metropolitanas.

\section{FUENTES Y METODOLOGÍA}

En un momento de expectación por las posibilidades investigadoras que pueda conllevar el Censo de Población y Viviendas de 2021 (INE), basado en nuevas metodologías de producción (Treviño y Domingo, 2020) no faltan las oportunidades de desarrollo de estudios metropolitanos empíricos a distintas escalas, a partir de la integración de fuentes estadísticas y cartográficas diversas.

A nivel nacional, además de las convencionales fuentes censales y padronales, es destacable el interés de los microdatos de la Estadística de Variaciones Residenciales (INE) para analizar la movilidad residencial en entornos metropolitanos. Es importante precisar que esta fuente no está exenta de limitaciones, como la anulación de identificación posible del municipio de origen/destino de cada vector cuando éste nace o finaliza en municipios con menos de 10.000 habitantes. Esto ensombrece las posibilidades de analizar la movilidad residencial en términos municipales de volumen modesto situados en entornos metropolitanos, los cuales son frecuentes en las áreas metropolitanas de tamaño medio, como el caso que nos ocupa. Otro aspecto cuestionable es la posible infra o supra valoración de la movilidad, que puede ser producido por cambios residenciales que no se registraron administrativamente $\mathrm{o}$, incluso, modificaciones de empadronamiento que no llegaron a ser efectivas en la realidad (Martí y Ródenas, 2006) a lo que podríamos añadir también cierto desfase temporal entre la realización del cambio y la comunicación administrativa (Susino, 2011). Sin embargo, las observaciones referidas a la fuente no son obstáculo para que la Estadística de Variaciones Residenciales y, especialmente, sus microdatos, se puedan interpretar como un recurso estadístico y cartográfico de interesantes posibilidades para medir la participación de las migraciones internas en la configuración de las áreas metropolitanas (García-Palomares y Pozo, 2010).

En relación con el hecho metropolitano, y siguiendo con las fuentes a nivel nacional, hay que tener en cuenta los nuevos productos estadísticos vinculados a los proyectos de Estadística Experimental del INE, en el marco establecido por el Sistema Estadístico Europeo, entre los que el estudio piloto de movilidad y los datos producidos con motivo de la pandemia COVID-19, arrojan luz sobre la movilidad diaria. Esta fuente ha sido de destacado interés para la realización de investigaciones geográficas en relación con la COVID-19, capaces incluso de vincular incidencia, contenido social y movilidad en entornos metropolitanos (Checa, Martín, López y $\mathrm{Nel} \cdot$ lo, 2020). Asimismo, la serie de datos de movilidad abre también oportunidades de análisis para estudios diversos en ámbitos metropolitanos donde, como es bien sabido, la movilidad se postula como un aspecto clave para la configuración de realidades funcionales en estos dinámicos entornos.

A nivel internacional, en este momento se dispone de bases cartográficas de interés sobre ámbitos urbanos europeos. Concretamente, en este estudio se incorporan datos producidos en el marco de la Unión Europea relativos a áreas urbanas funcionales que fueron establecidas por la Organización para la Cooperación y el Desarrollo Económicos (OECD en su acrónimo inglés) con criterios fijados a nivel europeo (Dijkstra y Poelman, 2012). Hay que tener en cuenta, además, que estas unidades de referencia son el marco para la medición de estadísticas relevantes en el proyecto Urban Audit (Feria, 2020) y que para el análisis de su evolución interna de coberturas se cuenta con el programa europeo Copernicus (Global Monitoring for Enviroment and Security. GMES, 2017) que alcanza su mayor nivel de actualización en los recientemente publicados conjuntos de datos de Urban Atlas 2018. 
Por otro lado, de producción europea, pero de alcance planetario, es interesante incorporar la fuente Global Human Settlement, con información raster a resolución de $1 \mathrm{~km}$, que aporta datos de utilidad sobre población, edificación y grado de urbanización de áreas urbanas con perspectiva temporal desde 1975 hasta 2015 (Selva-Royo, 2020). Esta fuente es clave para cuantificar aspectos asociados a algunas áreas metropolitanas europeas, como el descenso de la densidad de población (Guastella et al., 2019), aportando una aproximación precisa en lo que respecta al denominador de la densidad - la superficie-, en cuanto que no considera el área completa de la sección censal, sino el espacio edificado en el que se identifica población residiendo. Asimismo, con esta fuente, el estudio de la densidad no se referiría solo al binomio poblaciónsuperficie, sino también a la densidad edificatoria, entendida como la intensidad de ocupación del territorio.

El desarrollo del estudio a partir de las fuentes presentadas exige el planteamiento de metodologías basadas en el uso de Tecnologías de la Información Geográfica y, concretamente, en el diseño e implementación de proyectos SIG. A través de estas estructuras digitales de datos, se formulan distintas operaciones de análisis espacial y consultas temáticas y espaciales que resultan fundamentales para la obtención de los resultados que se presentan a continuación.

\section{RESULTADOS}

Un área de estudio, varias delimitaciones y enfoques posibles.

El área metropolitana de Santander fue identificada con nueve municipios según el modelo basado en una metodología multicriterio y en la lógica difusa, que fue realizado hace quince años (De Cos, 2005),

TABLA 1

COMPARATIVA DE DIMENSIONES DEL ÁREA METROPOLITANA (AM) Y EL ÁREA URBANA FUNCIONAL (FUA) DE SANTANDER, 2020

\begin{tabular}{|l|c|c|c|c|c|c|}
\hline \multirow{2}{*}{ Ámbito } & \multicolumn{2}{|c|}{ Municipios } & \multicolumn{2}{c|}{ Población } & \multicolumn{2}{c|}{ Superficie $\mathbf{k m}^{\mathbf{2}}$} \\
\cline { 2 - 7 } & No & $\%$ & Total & $\%$ & Total & $\%$ \\
\hline AM Santander & 9 & 8,8 & 279.599 & 48,1 & 302,4 & 5,7 \\
\hline FUA Santander & 21 & 20,6 & 381.666 & 65,6 & 685,7 & 12,9 \\
\hline Resto Cantabria & 72 & 70,6 & 199.975 & 34,4 & $4.640,50$ & 87,1 \\
\hline Total Cantabria & 102 & 100 & 581.641 & 100 & $5.326,20$ & 100 \\
\hline
\end{tabular}

Fuentes: EU, Copernicus Programme (Dataset) e INE, Urban Audit (Indicadores urbanos) y Padrón de Habitantes (2020). Elaboración propia. mientras que el área urbana funcional de Santander reconoce una realidad de veintiún términos municipales (Fig. 1). Ello tiene implicaciones importantes tanto en parámetros de superficie como de población (Tabla 1) que, como es lógico, muestran una representación absoluta y relativa dispar en el conjunto de la Comunidad Autónoma de Cantabria.

La diferencia de magnitud del área metropolitana y el área urbana funcional no se puede justificar por razones cronológicas, pues el área urbana funcional mantiene su límite exterior invariable desde las primeras bases cartográficas accedidas (2006) y el área metropolitana se delimitó en 2005. Frente a ello, se podría plantear que sus diferencias se deben a disparidades en los criterios de delimitación. Esto hace que resulte especialmente interesante estudiar los rasgos y procesos del área metropolitana de Santander (de nueve municipios) en el conjunto de su área urbana funcional identificada con criterios europeos (de veintiún municipios).

A continuación, se abordan los principales resultados obtenidos de los análisis y modelizaciones SIG en aspectos clave para el estudio de los ámbitos metropolitanos y los procesos periurbanos en la actualidad: cuál es la dinámica en la ocupación de suelo, cómo evoluciona la densidad de población, cómo son los cambios residenciales de la población del área y cuáles son las pautas de movilidad.

Cambios en las coberturas: abandono de la actividad agraria, artificialización y dispersión como procesos dominantes.

Los cambios de coberturas analizados intersecando las capas de Copernicus correspondientes a los años 2006 y 2018 derivan algo más de 20.000 polígonos en el área urbana funcional de Santander. De ellos, aproximadamente $85 \%$ no experimenta cambios de cobertura, si bien, lo más llamativo es que el $15 \%$ de zonas que sí cambian de orientación en el periodo 2006-2018 apenas representan el 7\% de la superficie. Se trata, por tanto, de unidades muy fragmentadas y de menor tamaño que las zonas correspondientes a usos invariables; de hecho, las zonas de cambio tienen una superficie media inferior a 2 hectáreas frente a algo más de 3,5 hectáreas en los polígonos que permanecen con la misma cobertura.

Atendiendo a cambios concretos, destacan, por un lado, modificaciones de cobertura producidas por el abandono de la actividad agraria y, por otro, cambios derivados del proceso de artificialización y dispersión por la expansión de usos urbanos. 
FIGURA 1

ENCUADRE TERRITORIAL COMPARATIVO DEL ÁREA METROPOLITANA Y EL ÁREA URBANA FUNCIONAL DE SANTANDER, 2018
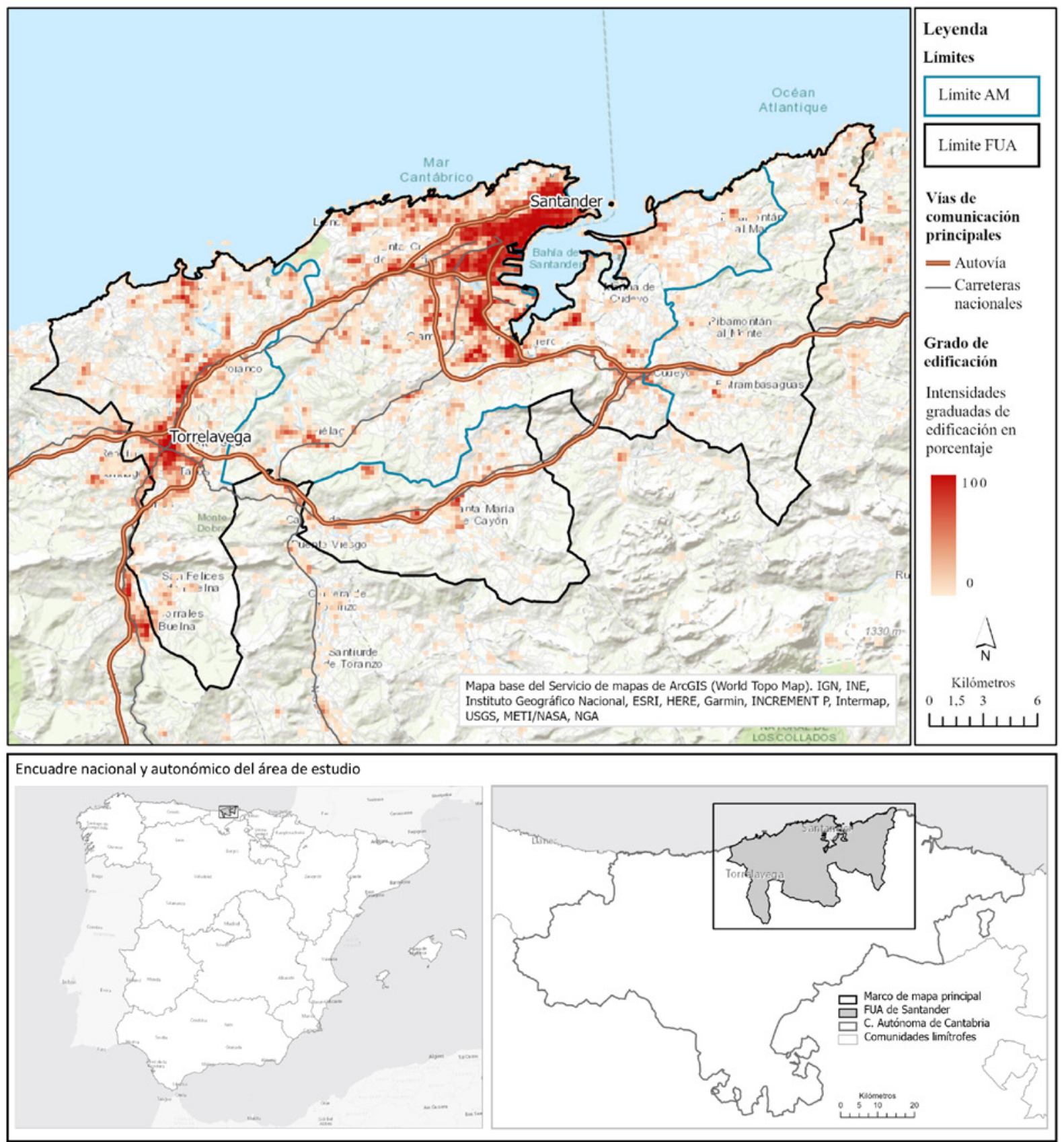

Fuentes: IGN, BCN 200; EU, Urban Atlas 2018. Copernicus Programme (Dataset) y GHS Dataset from Corbane, C., Florczyk, A., Pesaresi, M., Politis, P. y Syrris, V. (2018): GHS built-up grid 2014. Elaboración propia.

En lo que respecta al primer tipo de cambio en magnitud, el abandono de la actividad agraria está presente en algo más del $40 \%$ de la superficie que experimentó cambios. En la mayor parte de los casos se materializa en la transformación de espacios agra- rios a áreas de vegetación natural. Las zonas que experimentan estos cambios se encuentran distribuidas fundamentalmente en amplias manchas en los municipios del sur del área urbana funcional, la mayoría fuera de la delimitación inicial del área metropolitana; 
ello podría ser interpretado como un aviso de futuras áreas de artificialización, en una fase de abandono de explotación ahora detectada, que puede originar el cambio de uso en años futuros.

Por otro lado, el proceso de artificialización y dispersión es el dominante en cuanto al número de zonas de cambio. El patrón mayoritario consiste en la sustitución de usos naturales por superficies artificiales que dan protagonismo a edificaciones y urbanizaciones aisladas (30\% de los polígonos que cambian) que presentan una gran atomización y dispersión (De Cos, 2020). El siguiente cambio detectado es la transformación de la cobertura natural en zonas de usos económicos (industriales, comerciales, etc.) que se ubican tanto dispersas periféricas en el área urbana funcional como en las proximidades de los principales núcleos (Santander, Torrelavega y núcleos del arco occidental de la Bahía de Santander, especialmente Maliaño y Astillero). Estas localizaciones principales no lo son sólo en cuanto a volumen de población, sino también en lo que respecta a concentración de actividades económicas en el arco occidental de bahía. Así, destacan las grandes superficies comerciales, que a su vez actúan como motores de atracción de nuevos espacios residenciales, a lo que se suma la presencia de importantes superficies e instalaciones industriales, herencia de las pautas dictadas por la principal figura comarcal que tuvo este ámbito, el Plan Comarcal de 1955.

\section{Aumenta la población, pero disminuye la densidad.}

El estudio de la población en el territorio a nivel intraurbano se encuentra con frecuencia condicionado por cuestiones propias de las fuentes demográficas más habituales (censos y padrones) que ofrecen datos agregados a nivel de sección censal. Los cambios en la propia configuración de las secciones a lo largo del tiempo generan el conocido problema de la unidad espacial modificable para análisis evolutivos, por la inconsistencia temporal que suponen los cambios de delimitación de las unidades de referencia (De Cos, 2004). A ello se añaden debilidades metodológicas derivadas de la agregación de datos a niveles de escasa significación desde el punto de vista geo-demográfico, como son las mencionadas secciones, lo que puede estar detrás de buena parte de los patrones espaciales obtenidos.

Como alternativa, en el estudio evolutivo de la densidad en el área urbana funcional de Santander, se analiza la fuente Global Human Settlement. Los resultados evidencian que en los dos periodos considerados (1990-2000 y 2000-2015) se reducen las superficies no edificadas a un ritmo medio anual cercano a $-0,2 \%$ durante veinticinco años (Fig. 2). Por el contra-
FIGURA 2

TASAS DE CRECIMIENTO MEDIO ANUAL DEL ESPACIO EDIFICADO EN EL ÁREA URBANA FUNCIONAL DE SANTANDER, 1990-2015

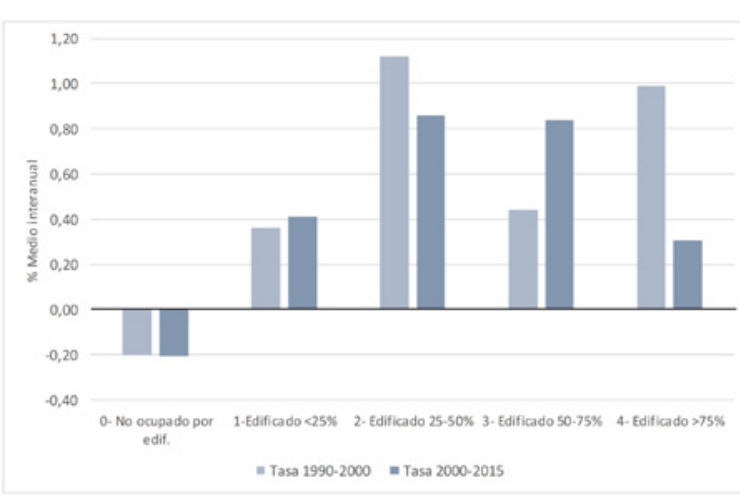

Fuente: GHS Dataset from Corbane, C. et al. (2018): GHS built-up grid 1990, 2000, 2014. Elaboración propia.

FIGURA 3

EVOLUCIÓN DE LA POBLACIÓN TOTAL Y LA DENSIDAD EN EL ÁREA URBANA FUNCIONAL DE SANTANDER, 1990-2015

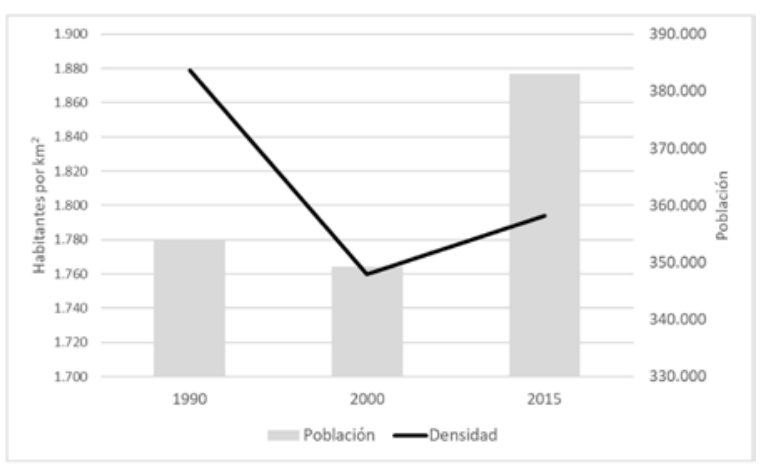

Fuente: GHS Dataset from Corbane, C. et al. (2018): GHS built-up grid 1990, 2000, 2014. Elaboración propia.

rio, en las zonas edificadas se detecta un incremento en aumento de zonas con edificación inferior al $25 \%$, que suponen la mayor extensión del suelo edificado con cerca de $150 \mathrm{~km}^{2}$ en el último año considerado. En cambio, las zonas de mayor intensidad de ocupación y densidad, esto es, con edificación superior al 75\%, a pesar de seguir creciendo, lo hicieron mucho más intensamente en el periodo 1990-2000 que en el 20002015. Se puede, por tanto, plantear que el proceso de expansión continúa. Esto queda de manifiesto en la reducción progresiva del suelo no edificado, en el incremento de zonas con niveles de edificación bajos (inferiores al $25 \%$ ) y en el menor crecimiento relativo de áreas edificadas densas y consolidadas (niveles superiores al 75\%). 


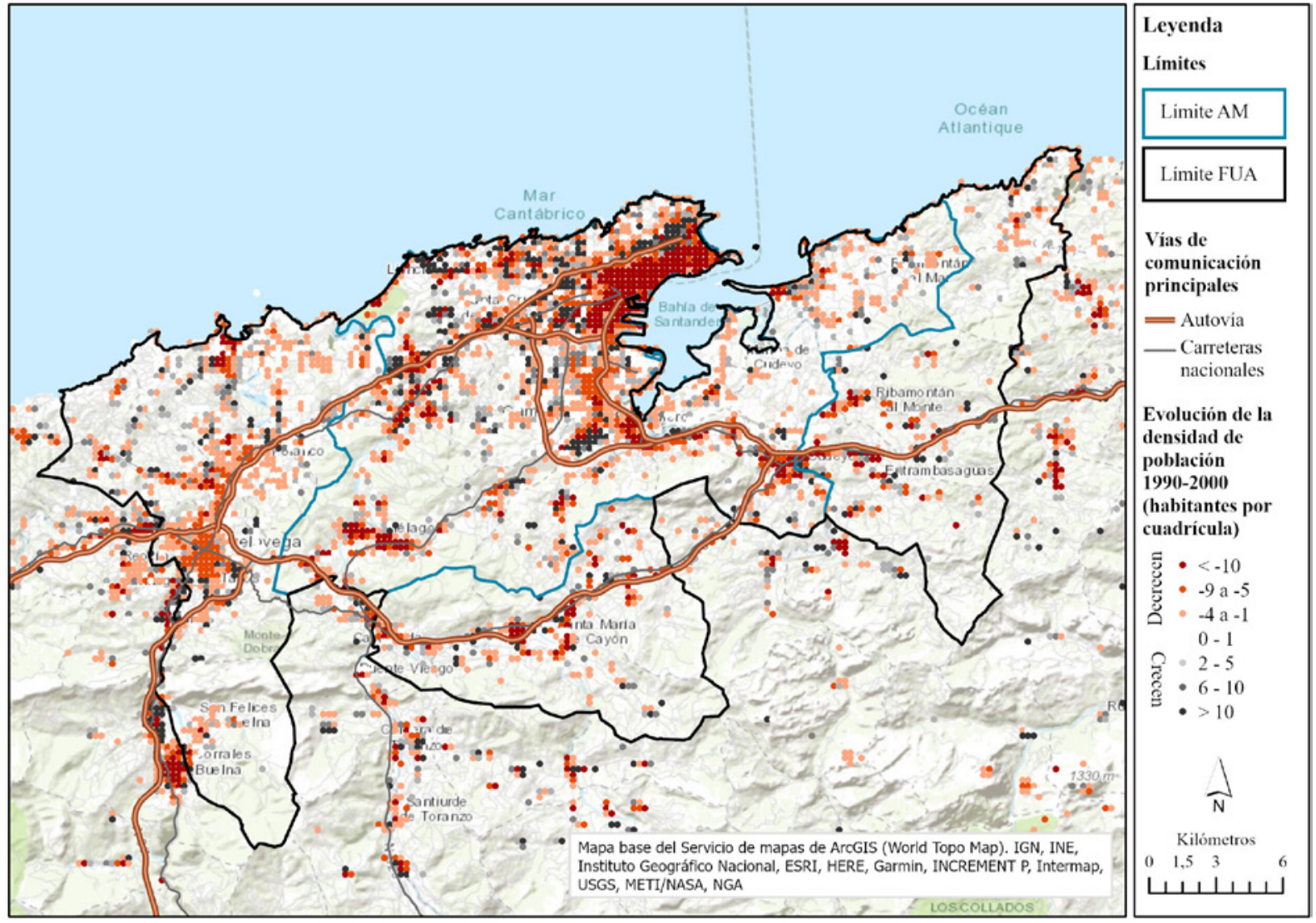

Fuentes: IGN, BCN 200; EU, Urban Atlas 2018. Copernicus Programme (Dataset) y GHS Dataset from Corbane, C. et al. (2018): GHS built-up grid 1990 y 2000. Elaboración propia.

Aludiendo a la población que reside en el área urbana funcional y el espacio edificado que ocupa, también se puede apuntar hacia un descenso de la densidad. Tomando como referencia los años 1990, 2000 y 2015, y considerando la población total residente en el área y la superficie del espacio residencial, se observa un crecimiento de la población constante que -especialmente en el primer periodo- va acompañado de un descenso importante de la densidad; ese decenso es producto de la expansión superficial del espacio residencial de forma dispersa y discontinua, lo que como efecto derivado conllevó una reducción de la densidad de población (Fig. 3). Así, si en 1990 residían en la zona analizada 353.832 habitantes con una densidad media de 1.879 habitantes por kilómetro cuadrado, en 2015 la población total del área urbana funcional de Santander ascendía a 383.014 habitantes, pero la densidad era de 1.794 habitantes por kilómetro cuadrado. Si se hubiera optado por una contención del proceso de artificialización dispersa, con ese volumen de población en el último año analizado, el conjunto debería presentar una densidad en torno a 1.930 habitantes por kilómetro cuadrado.

A pesar de que la Fig. 3 muestra cierto repunte de la densidad entre los años 2000 y 2015, hay que analizar este dato en términos generales y se constata que el área urbana funcional de Santander ha experimentado un descenso de la densidad de población en los espacios edificados si se tiene como punto de referencia 1990, cuando aún el sistema no había presentado la tendencia descentralizadora que ha marcado los periodos posteriores.

Así, tal como muestra la Fig. 4, es en el año 2000 cuando se empiezan a manifestar los efectos territoriales de la descentralización y de los cambios residenciales desde la ciudad central a la periferia. Esta pauta puede ser interpretada como una imitación por parte de las ciudades medias de lo que aconteció con una década de adelanto en los principales sistemas urbanos de España (De Cos y De Meer, 2013). Ese primer periodo muestra un patrón 
muy claro de descenso de densidad de población en los centros urbanos de los principales núcleos del sistema (fundamentalmente Santander, pero también Torrelavega, Astillero o Solares). Por el contrario, pequeñas zonas muy dispersas y atomizadas llaman la atención por el incremento de la densidad de población siguiendo elementos de referencia, como la proximidad a los principales ejes de comunicación y a los núcleos del sistema. Este mapa es la muestra expresiva de lo que anteriormente se identificaba como proceso de artificialización difusa del territorio, medida en este caso a partir del número de habitantes por cuadrícula.

Según los análisis realizados a partir de la fuente Global Human Settlement, la tendencia detectada cambia en el segundo periodo considerado (20002015) ya que, como muestra la Fig. 5, parece frenarse la pérdida de población de los principales núcleos del sistema y, por otro lado, se acentúa la dispersión iniciada en el periodo precedente. En las zonas centrales de Santander y Torrelavega se detecta una falta de coincidencia entre el patrón espacial que aporta esta fuente en el periodo 2000-2015 y la información padronal. Así, los centros de las principales ciudades del sistema tornan ahora en tonos grises manifestando leves incrementos de población que podrían cuestionar la validez de la fuente en ese periodo para enfoques evolutivos en zonas urbanas consolidadas. Para la temática que nos ocupa, y centrándonos en los patrones del periurbano, se constata que las tímidas manchas grises dispersas del periodo anterior presentan ahora cierta expansión y continúa su multiplicación a partir de nuevas ubicaciones que reproducen una pauta de distribución similar, en torno a espacios bien comunicados y próximos a otros núcleos del sistema.

\section{Intensidad y diversidad de variaciones residenciales.}

El estudio de las variaciones residenciales es especialmente significativo en entornos metropolitanos cuando se cuenta con localización de origen y destino. Esto permite la explotación de la fuente a modo de vec-

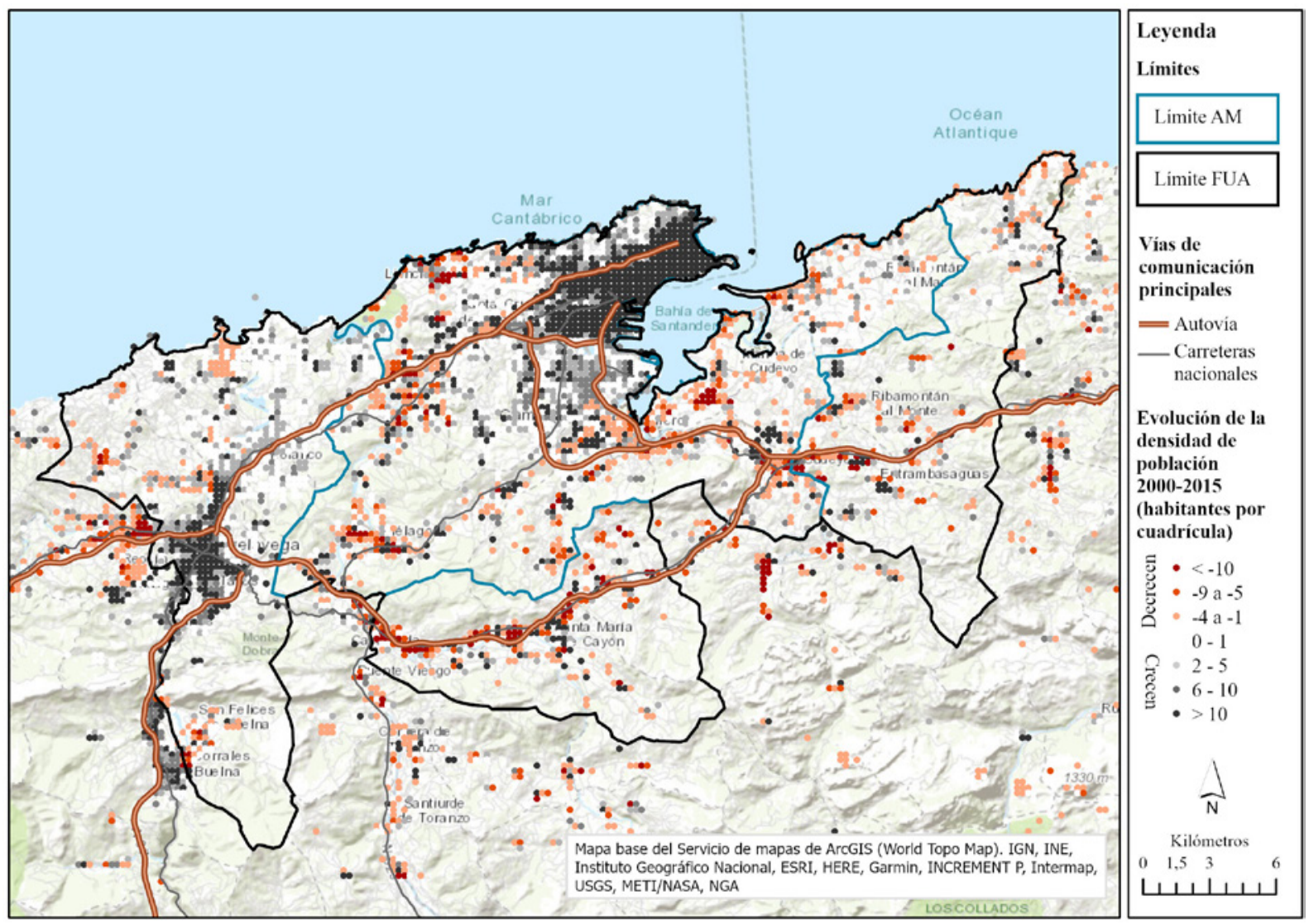

Fuentes: IGN, BCN 200; EU, Urban Atlas 2018. Copernicus Programme (Dataset) y GHS Dataset from Corbane, C. et al. (2018): GHS built-up grid 2000 y 2014. Elaboración propia. 
tor, si bien es preciso recordar que los microdatos de la Estadística de Variaciones (INE) sólo incluyen el municipio de origen-destino del vector cuando los términos municipales tienen un volumen de población superior a 10.000 habitantes. A pesar de esta observación, se obtienen 406 vectores georreferenciados de desplazamientos agregados con origen y/o destino en un municipio de Cantabria, que representan 10.306 cambios residenciales. Un total de 303 vectores (el 75\%) afectan a alguno de los veintiún municipios de la FUA de Santander y representan los cambios residenciales de 8.346 registros para los que se conoce origen y destino, prueba por tanto del elevado dinamismo de este ámbito de Cantabria por movilidad residencial (los veintiún municipios del área urbana funcional de Santander están implicados en algo más del $80 \%$ de los cambios residenciales de la comunidad autónoma).

Desde una perspectiva de conjunto, destaca el hecho de que los principales polos de atracción de altas residenciales tienen una disposición contrastada, tan- to al este como al oeste de la mayor ciudad del sistema, Santander. En cambio, los municipios del arco occidental de la bahía, como Camargo o El Astillero, que ejercieron de polos de atracción a principios del presente siglo, en los últimos años han debilitado su función de destino de las variaciones residenciales regionales (Fig. 6). Asimismo, los coeficientes de localización manifiestan la escasa capacidad de atracción de los principales municipios del sistema, Santander y Torrelavega, ambos con menos altas que las que les correspondería por su volumen de población.

Del análisis cartográfico y estadístico de las relaciones espaciales se confirma la existencia de dos polos importantes en el área urbana funcional - Santander y Torrelavega - con escaso diálogo territorial entre sí en cuanto a movilidad residencial. En este sentido, es fundamental considerar los coeficientes de localización de los vectores que corresponden a bajas de Santander y de Torrelavega (Fig. 7), ya que permiten analizar si hay intercambio residencial representativo

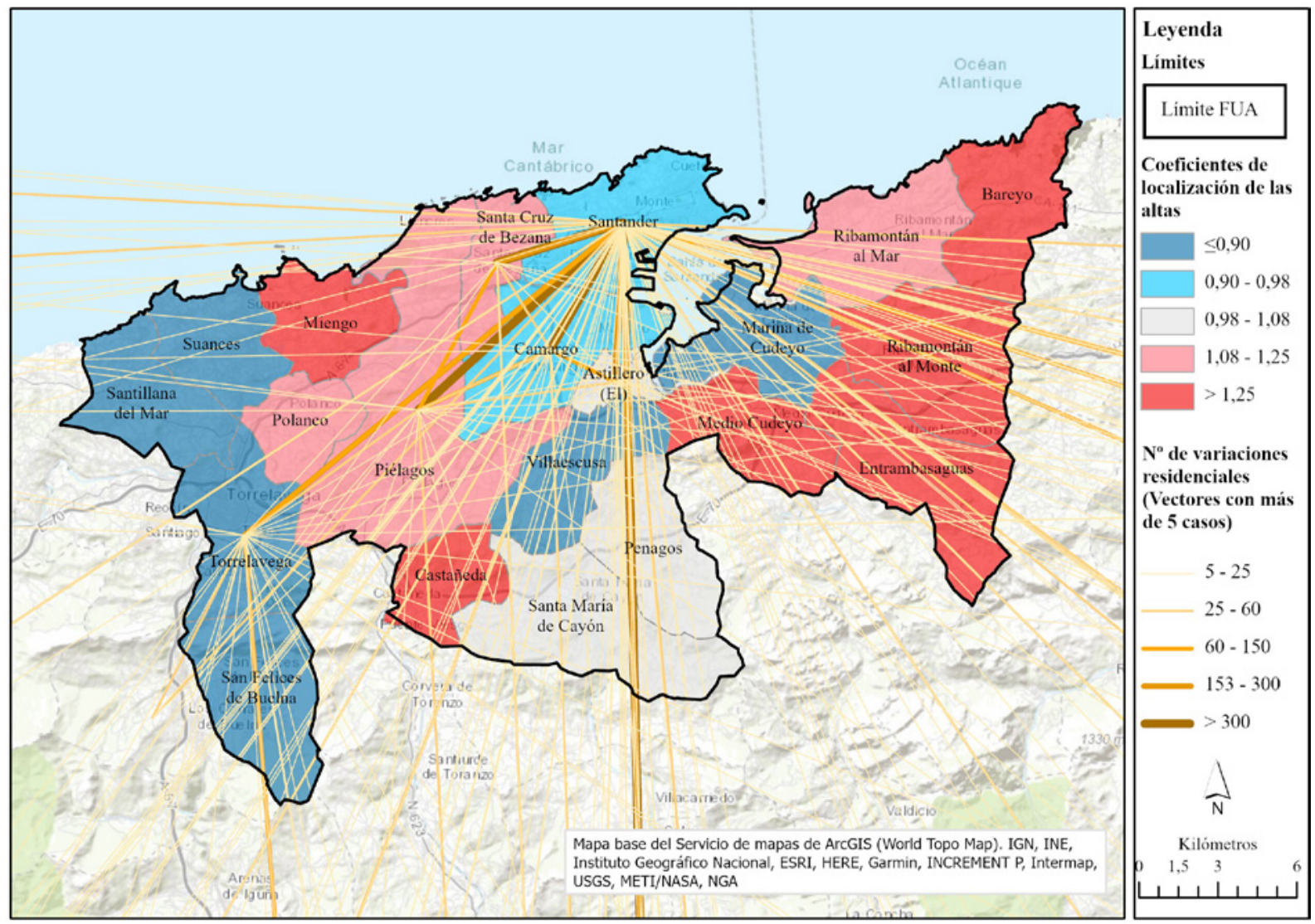

Fuentes: IGN, BCN 200; EU, Urban Atlas 2018 e INE, Estadística de Variaciones Residenciales 2017 (Microdatos) y Padrón Municipal de Habitantes (2019). Elaboración propia. 
FIGURA 7

COEFICIENTES DE LOCALIZACIÓN SEGÚN LOS MUNICIPIOS DE DESTINO (ALTAS) DE LAS BAJAS RESIDENCIALES DE SANTANDER Y TORRELAVEGA, 2017

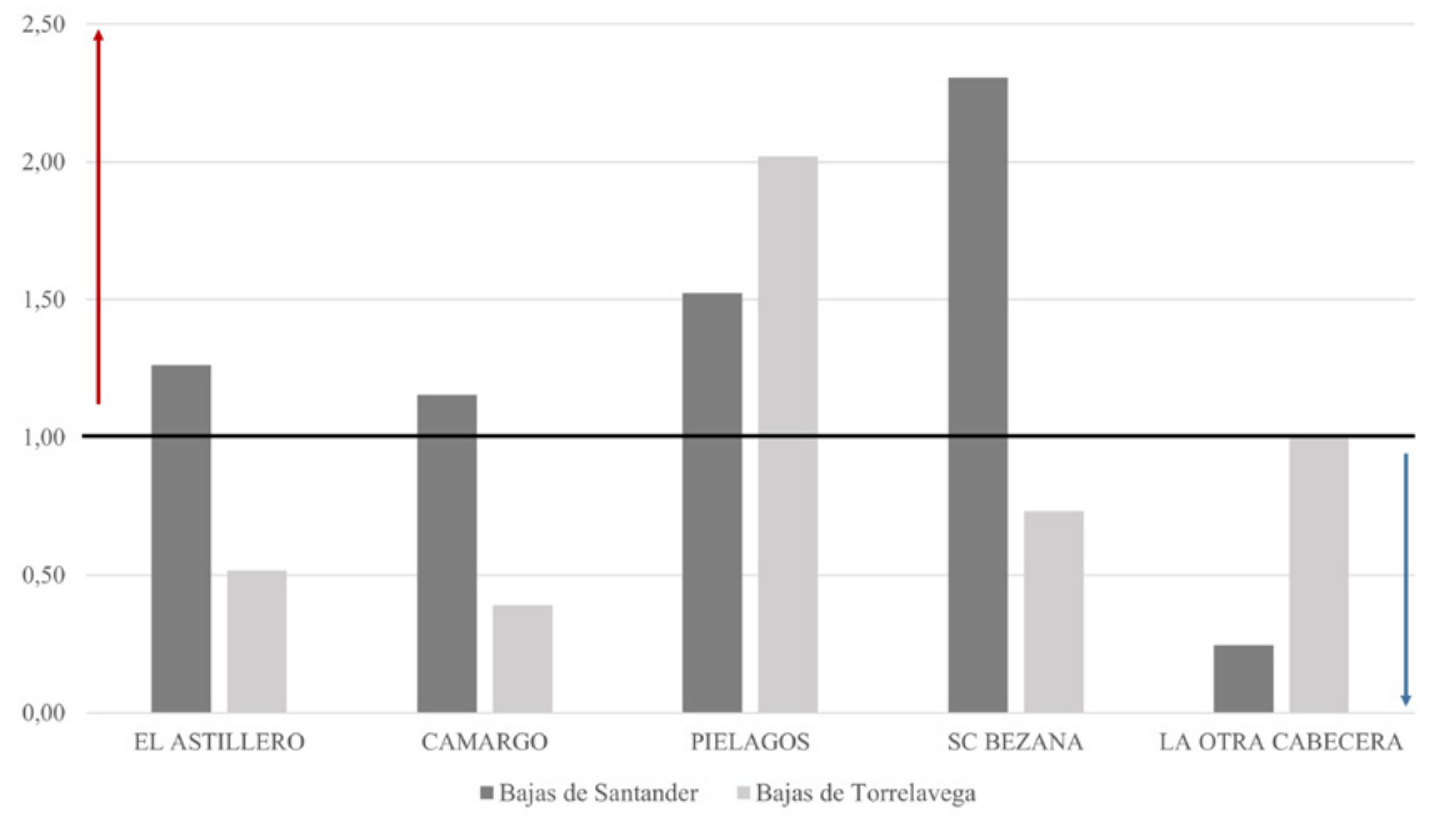

Fuente: INE, Estadística de Variaciones Residenciales 2017 (Microdatos) y Padrón Municipal de Habitantes (2019). Elaboración propia.

en términos relativos, considerando el tamaño municipal dispar de los municipios receptores.

Las bajas del municipio de Santander con destino conocido en el área urbana funcional se desplazan hacia los municipios más próximos, parte de ellos colindantes, todos con una tendencia progresiva desde que comenzara la expansión metropolitana en el ámbito analizado. Además, se da una segunda circunstancia, que es la buena comunicación entre los principales destinos de la variación residencial y el municipio de Santander, al localizarse a escasos 10 minutos en vehículo y en todos los casos conectados por autovía. Por el contrario, el coeficiente de localización con destino Torrelavega, segundo núcleo del área urbana funcional, es realmente bajo (infrarrepresentado en relación con el tamaño de Torrelavega, esto es, coeficiente inferior a 1, concretamente $0,25)$. Asimismo, las bajas de Torrelavega solo llegan a Santander con coeficiente 1 (valor que correspondería según el tamaño de Santander). Por tanto, si bien el municipio principal del área urbana funcional tiene mayor atracción sobre Torrelavega, hay que tener presente que sigue siendo un valor no destacable, mientras que el receptor más importante de las variaciones salientes de Torrelavega hacia el área urbana funcional es el municipio colindante Piélagos. Es interesante el hecho de que el municipio de Piélagos, de amplia superficie, polarice buena parte de las variaciones residenciales de Torrelavega, teniendo en cuenta que está situado en dirección a Santander y comunicado por autovía con la ciudad principal. Parece que, una vez más, se confirma el papel de Piélagos como municipio bisagra entre los dos polos del sistema: Santander y Torrelavega.

De hecho, es en el ámbito que media entre ambos polos donde se produce un mayor dinamismo en cuanto a las variaciones residenciales, tal como demuestra la tasa neta de variación residencial (Fig. 8). Se revela un arco de municipios entre Santander y Torrelavega con destacadas tasas de variación residencial positivas. Esta tasa, por otro lado, permite la confirmación de los resultados obtenidos en los coeficientes de localización: Santander y Torrelavega presentan tasas levemente positivas, en ambos casos gracias a las variaciones residenciales externas $y$, por otro lado, los municipios del arco occidental de la bahía tienen comportamientos erráticos, ligeramente positivos o negativos, ejerciendo un papel secundario.

Adicionalmente, en dirección contraria a Santander, es preciso tener en cuenta que el municipio de Torrelavega cuenta con otros municipios destino de sus bajas residenciales en los colindantes por el oeste, fundamentalmente Cartes y, en menor medida, Reocín. Ambos municipios reciben prácticamente el $20 \%$ de la 
población que sale de Torrelavega para residir en otro municipio de Cantabria. Sin embargo, contrariamente a lo esperado, Cartes y Reocín no se encuentran incluidos en la delimitación actual de veintiún términos municipales que integran el área urbana funcional, aspecto que abriría una línea de cuestionamiento de esa unidad de referencia, al menos a escala regional.

\section{Movilidad diaria que confirma la configuración de un área polinuclear.}

La movilidad obligada por trabajo en el área urbana de Santander, según los indicadores de áreas urbanas del INE, se realiza en un $54 \%$ de los casos en coche, siendo los desplazamientos a pie y en transporte público cercanos al $10 \%$ en ambos casos. Se trata en su mayoría de desplazamientos cortos en tiempo (por término medio unos 18 minutos), dadas las dimensiones del área y la presencia de diversos tramos de autovía (S-10, S-20, S-30 y A-67).
Los datos de movilidad proporcionados por el INE demuestran la existencia de áreas de movilidad con capacidad de atracción diaria (saldos positivos en el balance entrada-salida) en buena parte de los distritos de Santander y Torrelavega (Fig. 9); a ellos se suman, si atendemos a valores absolutos, parte de los municipios del arco de la bahía (incluidos en el área metropolitana inicialmente delimitada) como son Camargo y El Astillero, que a pesar de presentar un saldo levemente negativo, cuentan con un volumen importante de población durante el día que no reside en el territorio municipal. Por el contrario, en el interior y en el sur del área urbana funcional, se identifican claramente municipios de carácter residencial que emiten diariamente más población de la que reciben. Es el caso de Piélagos, Polanco, Villaescusa, Medio Cudeyo, o Santa María de Cayón, entre otros. Se observa que el volumen de población que permanece en estas áreas durante el día sin ser residente es realmente

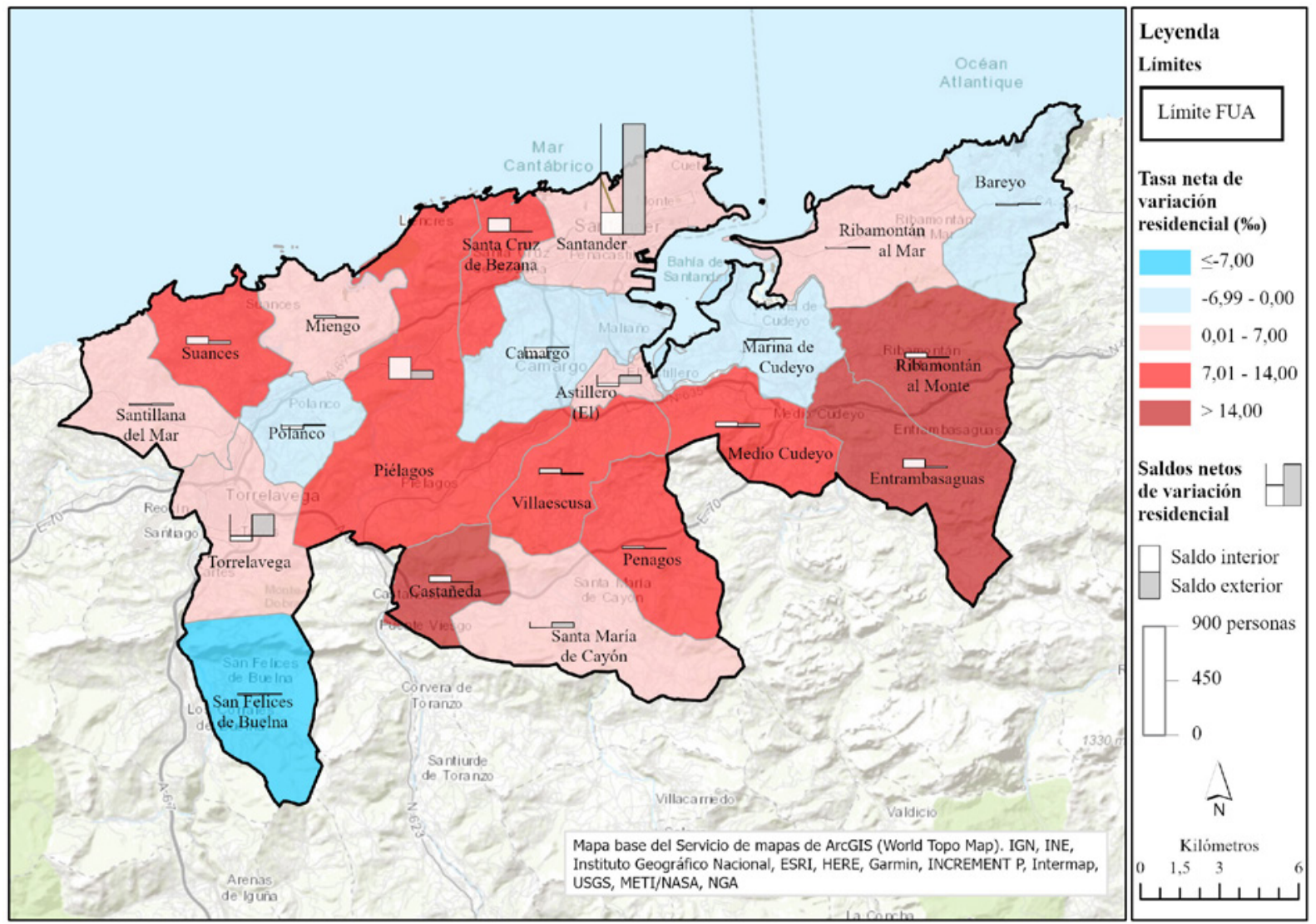

Fuentes: IGN, BCN 200; EU, Urban Atlas 2018 ee Instituto Cántabro de Estadística (ICANE), Altas, bajas y saldo por variación residencial interna y externa por municipios, a partir de INE, Estadística de Variaciones Residenciales 2017. Elaboración propia. 


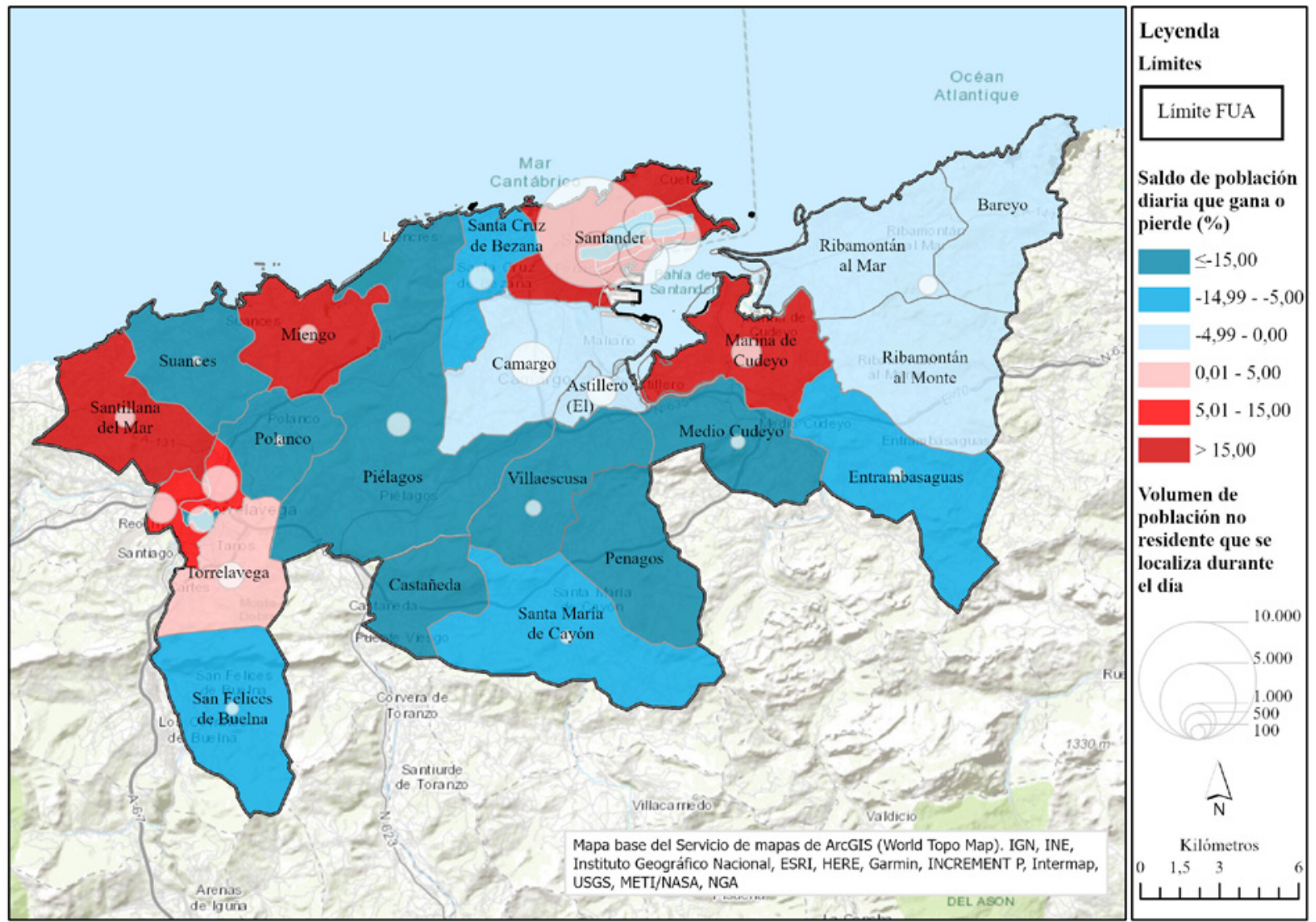

Fuentes: IGN, BCN 200; EU, Urban Atlas 2018 e INE, Estadística Experimental: Estudio de movilidad a partir de la telefonía móvil, 2019. Elaboración propia.

bajo (entre 100 y 500) frente a los 5.000-10.000 que llegan a registrarse en algunos distritos del municipio de Santander.

Así, Santander y Torrelavega se comportan como dos focos de atracción de la movilidad y entre ambos enmarcan un ámbito de intensa movilidad diaria con destinos que se cruzan, tanto hacia y desde los municipios principales como entre el resto de los municipios del área funcional.

Considerando los flujos, una vez más se confirman las fuerzas contrapuestas ejercidas por Santander y Torrelavega sobre su entorno. Además, ambos polos presentan una intensa movilidad interna (el $70 \%$ y el $65 \%$ respectivamente de los desplazamientos en esos municipios corresponden a población residente que cambia de distrito durante el día dentro del mismo municipio de residencia).

Si analizamos los cambios de municipio por movilidad diaria, Piélagos — el referido municipio bisagra- es uno de los que presenta mayor variedad de vinculación a distintas áreas residenciales (concretamente más de 30 áreas distintas son destino de las salidas diarias de este municipio) si bien, el 35\% de las salidas se dirigen a Santander y cerca del $7 \%$ a Torrelavega. Destacada es, asimismo, la movilidad desde Piélagos a otros municipios del norte del área urbana funcional, como son sus colindantes Santa Cruz de Bezana y Miengo. El vector de movilidad que representa la salida de Santander con destino Torrelavega es muy discreto (menos de 500 desplazamientos) contrastando con la fuerte vinculación de Santander hacia los municipios del arco de la bahía. En dirección contraria, solo un $10 \%$ de las salidas de Torrelavega tienen como destino Santander, a pesar del tamaño demográfico y la elevada concentración de actividades económicas de este polo en el conjunto considerado.

Los flujos más expresivos son los que hacen referencia a Santander y Torrelavega como focos de atracción de la movilidad desde otros municipios de perfil 
metropolitano-residencial. Ambos polos tienen áreas de influencia diferenciadas: Santander es destino de buena parte de los desplazamientos originados en municipios colindantes o próximos como Camargo, Piélagos, Santa Cruz de Bezana o El Astillero, mientras que Torrelavega destaca como destino de otro conjunto de municipios vecinos entre los que destacan por volumen Cartes y Reocín, colindantes a Torrelavega por el oeste, pero que paradójicamente - tal como se señaló anteriormente- no están incluidos en la delimitación de área urbana funcional reconocida actualmente según los criterios. A ellos se suma en tercer lugar Polanco, municipio que cuenta con un elevado perfil residencial y que se encuentra claramente vinculado a la expansión urbana de Torrelavega.

\section{DISCUSIÓN}

Los resultados obtenidos en el análisis realizado sobre el área urbana funcional de Santander avalan el planteamiento de Guastella et al. (2019) según el cual, los autores establecían varios métodos para medir el grado de expansión urbana, considerando tanto la superficie ocupada por las zonas urbanizadas, como la densidad de población y el grado de discontinuidad del crecimiento urbano según su distribución. En el análisis del área de Santander se ha abordado ese planteamiento a partir de la fuente Global Human Settlement para los dos primeros aspectos mencionados y las coberturas de Copernicus tratadas mediante SIG para considerar el grado de discontinuidad.

En relación con el uso de la fuente Global Human Settlement, en términos generales se considera su potencial para el estudio de los procesos de expansión urbana a nivel supramunicipal, aspecto que ya defendían algunos autores como Selva-Royo (2020) en relación con el estudio de la densidad. Sin embargo, los resultados obtenidos en el análisis del área urbana funcional de Santander a partir del conjunto de datos raster "population" del año 2015 dejan algunas incógnitas abiertas. Mientras que la diferencia de densidades entre 1990 y 2000 refleja el mismo patrón que la fuente padronal para las secciones censales, la evolución de la densidad de 2000 a 2015 parece aportar mayor crecimiento en los centros urbanos de Santander y Torrelavega que los padrones municipales (que en su mayoría siguen registrando pérdidas de población). Este decalaje puede ser debido a la diferente metodología de producción de las fuentes citadas. Aunque inicialmente podría evocar lo que algunos autores planteaban para los principales sistemas urbanos españoles como una vuelta al centro (López-
Gay, 2011), tras la comprobación realizada parece un argumento más probable que la fuente Global Human Settlement incluye alguna distorsión o cambio en la metodología de producción que afectaría a cálculos evolutivos: efectivamente, el nivel de decrecimiento de los centros urbanos del sistema se va matizando y suavizando, como producto precisamente de la fase de madurez en la que se encuentra el área urbana funcional de Santander. A pesar del cuestionamiento realizado sobre los resultados evolutivos, la fuente se ha mantenido en el estudio por su adecuación en las zonas periurbanas y en el periodo precedente 1990-2000 para el conjunto del área, así como por su elevado potencial para determinar la huella urbana configurada en distintos momentos de tiempo, con precisión de malla de $1 \mathrm{Km}$ y a escala planetaria (Melchiorri et al., 2018).

Por otro lado, y en relación con el planteamiento expuesto, los resultados obtenidos pueden relacionarse con la tipología de áreas urbanas funcionales europeas propuesta por Guastella et al. (2019) por la cual el área de Santander respondería a una pauta de incremento de población, descenso de densidad, y un comportamiento decreciente de la discontinuidad. Así, los resultados presentados anteriormente confirman ese enfoque y la situación del área de Santander en un estadio maduro, en el que efectivamente el área en su conjunto presenta una tendencia progresiva, con un incremento poblacional de algo más de 33.000 habitantes en los últimos 15 años; si bien, la expansión, la dispersión inicial y el descenso de la densidad evolucionan en un proceso que se va matizando en el último periodo analizado (2000-2015), lo cual puede interpretarse como una tendencia positiva, en realidad menos negativa, en clave de sostenibilidad.

Otros indicadores avalarían también las tendencias apuntadas y la fase de madurez en la que se encontraría el área de Santander, con cierta deceleración en la depredación de suelo a la que asistimos en el primer periodo analizado (1990-2000). Estos resultados coinciden con el planteamiento de López-Gay (2016), que asocia la madurez de los sistemas urbanos a una disminución de la magnitud de los cambios territoriales.

Sin embargo, constatar un estadio de madurez no puede llevarnos a una relajación en el abordaje del modelo urbano español. De hecho, la España urbana actual es producto de una evolución de décadas causante de problemas importantes desde el punto de vista de la sostenibilidad, tal como se planteó en el apartado introductorio. Es cierto que en los principales sistemas urbanos se está constatando también 
una reducción de los ritmos de expansión territorial, más en Barcelona que en Madrid y también en otros sistemas, como Sevilla (De Oliveira, 2018). Aunque décadas atrás la inversión de tendencia - de centrípeta a centrífuga - en los principales sistemas urbanos españoles sirvió de preludio de lo que ocurriría posteriormente en las ciudades medias, aún es pronto para saber si esta pauta madura será estable en el tiempo y generalizada para la mayoría de las ciudades medias.

Centrándonos en los hechos constatados, y ante la dificultad de neutralizar el efecto de la escala para comparar unos casos con otros, Artmann et al. (2019, p. 6) plantearon como alternativa para medir la expansión dispersa un indicador basado en el "consumo de suelo per cápita". En la etapa de mayor artificialización y dispersión se detectan mayores ratios de suelo por persona; así, en el área urbana funcional de Santander los residentes de 1990 consumían $532 \mathrm{~m}^{2}$ per cápita, ratio que se dispara - producto del periodo más expansivo hasta el año 2000- alcanzando 568 $\mathrm{m}^{2}$ per cápita, para bajar levemente en 2015 hasta los $557 \mathrm{~m}^{2}$ per cápita, lejos todavía del valor contenido de partida en 1990.

Esta pauta de artificialización y dispersión, lamentablemente, no es exclusiva del ámbito analizado. Olazabal y Bellet (2016) comprobaron los altos niveles de artificialización y urbanización dispersa a partir de su estudio sobre 62 áreas urbanas españolas, mediante el seguimiento de cambios de coberturas Corine Land Cover. Los autores demostraron que el patrón iniciado y protagonizado por los principales sistemas urbanos del país, en el último periodo tiene como protagonistas a las ciudades medias. Se confirmaría, así, una de las ideas iniciales que señalábamos en el título del presente trabajo: el periurbano ha cobrado vida propia, y según los autores citados, esta pauta parece producirse tanto en la periferia como en la periferia de la periferia. Esto es, con enfoque multiescalar, periférico inicialmente con perspectiva de país, pero también periférico en cada aglomeración urbana, a nivel de estudio de caso.

Respecto a Santander, el estudio referido aporta indicadores interesantes que corroboran los resultados de la presente investigación. Según Bellet y Olazabal (2016) el ritmo de crecimiento anual medio de la población del área de Santander entre 1991 y 2011 era de $0,28 \%$, y lo más importante es que no tuvo un reflejo espacial proporcional, sino exagerado, con un ritmo medio de crecimiento del suelo artificial de 1,25\% entre 1987 y 2011 y cercano a 1,9\% si se considera solo el último tramo del estudio de 2000 a 2011.
Los indicadores señalados no hacen sino confirmar los procesos de artificialización y descenso de la densidad concretados con perspectiva espacial en el presente estudio, con una superficie artificial que crece a un ritmo mucho más elevado que la progresión de la población. Este comportamiento no es exclusivo de Santander, sino que en el trabajo referido se confirma un modelo de urbanización extensa similar en varios sistemas de tamaño medio, como: Castellón, Pamplona o Vitoria, entre otros.

La falta de acoplamiento de las tasas de crecimiento del binomio población-territorio puede ser explicado por la localización periférica de nuevos suelos artificiales destinados a usos residenciales, pero de baja densidad, así como por una artificialización dirigida a otros usos no residenciales, fundamentalmente de actividades económicas y también de servicios e infraestructuras (Oliveras y Cartanyà, 2015; Olazabal y Bellet, 2019); esos aspectos también han sido comprobados en este estudio para el área urbana funcional de Santander, a partir del análisis realizado de cambios en las coberturas de Copernicus.

Por otro lado, los aspectos considerados de flujo (variaciones residenciales y movilidad) son fundamentales para el estudio de las áreas metropolitanas y funcionales en la actualidad. Oliveras y Cartanyà (2015) cuestionaron los polígonos envolventes de las áreas urbanas funcionales de Tarragona y Reus (colindantes pero diferenciadas en Urban Atlas) y plantearon, con un enfoque convergente con el presente estudio de Santander, las posibilidades de adaptación de la delimitación de áreas urbanas funcionales en función de otros rasgos, fundamentalmente demográficos y de movilidad. El matiz diferenciador del estudio citado y el presente trabajo radica en que en el análisis sobre Tarragona y Reus no se planteó una comparativa territorial entre área metropolitana y área urbana funcional, sino más bien una aproximación centrada en determinar si se trataba de una sola o dos áreas o sub-áreas funcionales.

Es frecuente contar con investigaciones centradas en determinar si los sistemas urbanos responden a la tipología polinuclear, aspecto también abordado y comprobado en el caso de Santander a través de las mencionadas variables de flujo. El interesante estudio de Gómez, Sá Marques y Hernández (2020) establece 273 delimitaciones alternativas de áreas funcionales en la Península Ibérica, en función de la concentración de población y actividades en un núcleo y la dependencia de su área de influencia, con un enfoque a modo de red, con elevada participación del mercado 
laboral y las pautas de commuting. Según los autores, Santander se encontraría en el segundo nivel del ranking de metropolización como "sistema protometropolitano" con más de 200.000 habitantes, al igual que otros sistemas españoles de mayor tamaño (Granada, A Coruña, o los conjuntos Donostia-Errentería-Irún y Tarragona-Reus-Cambrils) y de menor volumen (es el caso de Valladolid, Castellón, Pamplona, Córdoba, Vitoria o Huelva). Esta tipología sólo sitúa por encima la categoría de "sistemas metropolitanos" para más de 500.000 habitantes, nivel que queda reservado a las grandes áreas metropolitanas de nuestro país. Según Gómez et al. (2020) el sistema de Santander entre 1991 y 2011 se comportó de forma expansiva, como la inmensa mayoría de áreas urbanas funcionales identificadas en el citado estudio. Sin embargo, obtuvieron un rasgo particular en cuanto a policentrismo se refiere, que confirma los resultados aportados en esta investigación, a otra escala y con otras fuentes de base. El área urbana funcional de Santander se comporta como un sistema claramente policéntrico, propiedad que solo se adjudica a diez casos en la Península Ibérica y, concretamente, Santander-Torrelavega está entre los casos de mayor tamaño en los detectados en España, junto a Cádiz-Jerez y Almería-Campo de Dalías. De hecho, lo más cercano que establece el modelo de Gómez et al. (2020), en un nivel de policentrismo inmediatamente inferior, son modelos de tipo "parcialmente policéntrico", donde se encontrarían Málaga-Marbella, Bilbao, Donostia-Errentería-Irún o el área de Castellón, entre otros. Marmolejo, Ruiz y Tornés (2015), tras establecer un indicador de policentricidad en su estudio sobre las siete principales áreas metropolitanas españolas, también con elevado peso de la movilidad laboral, concluyeron que el policentrismo es un proceso, y no puede ser considerado como algo estático o finalizado. Ese es el punto en el que se queda el análisis detallado del área urbana funcional de Santander: la confirmación de que estamos ante un sistema policéntrico, pero con cuestiones aún pendientes de determinar en el tiempo.

Quedaría por concretar si es un sistema bicéfalo (Santander-Torrelavega), o si responde a otra estructura. En este sentido, es interesante el enfoque de Münter y Volgmann (2020) centrado en una revisión terminológica profunda sobre el policentrismo en Europa y la génesis y características de regiones policéntricas, que nos llevarían a interpretar que el área urbana funcional de Santander corresponde a una región policéntrica post-suburbana, caracterizada por la presencia de un centro dominante, Santander, y otros subcentros de menor tamaño - fundamentalmente Torrelavega, pero también Maliaño o Astillero-. Ante la relativa estabilidad en el tiempo de esos subcentros, esto es, no se está en una etapa de emergencia de nuevos subcentros, podría entenderse que el sistema se encuentra en una fase estática en lo que a su policentrismo se refiere. No obstante, una comprobación de esta hipótesis sería necesaria en futuros trabajos. La existencia de esta estructura y la proximidad entre el centro dominante y los subcentros generaría una serie de sinergias, interconexiones y relaciones entre los distintos núcleos del sistema que los análisis de movilidad residencial y diaria han manifestado como evidentes.

En este sentido, una vía de profundización de la investigación presentada podría orientarse precisamente a modelizar la estructura del sistema a partir de centros y subcentros, abordando el policentrismo como un proceso (Marmolejo et al., 2015) y profundizando a partir de un análisis de flujos más exhaustivo en la movilidad residencial y diaria, con registros de microdatos a medida que superen algunas de las limitaciones iniciales de las fuentes, ya apuntadas anteriormente. Sería interesante también contemplar las pautas evolutivas de la movilidad residencial, ya que es una variable clara para conocer el modelo de desarrollo urbano-metropolitano de una ciudad y su organización, o incluso optar por fuentes alternativas, como encuestas o datos de geolocalización relativos al uso de redes sociales, que han arrojado resultados de interés para acotar lo urbano con una perspectiva dinámica en otros casos de estudio, como Valencia a partir del uso de datos de la red Twitter (Zornoza, 2019).

Por otro lado, atendiendo a los resultados obtenidos, quedan cuestiones planteadas en las que es necesario profundizar una vez comprobado el carácter polinuclear del área urbana funcional. Es posible cuestionar si Santander y Torrelavega deben integrar la misma unidad metropolitana (ahí está el primer matiz entre lo funcional y lo metropolitano en clave de gobernanza). En caso de que fuese así, los datos de movilidad demuestran que el área de influencia de Torrelavega requiere la incorporación de otros municipios colindantes en su sector occidental, como son Cartes y Reocín. Aún más, la sinuosa configuración del área urbana funcional cuestionaría su delimitación al sur, donde se observan claros huecos en el perímetro externo que han dejado fuera el municipio de Liérganes, ubicado entre dos municipios incluidos (Penagos y Entrambasaguas). Esto podría tener su justificación en el momento inicial de delimitación del área urbana funcional, pero hoy en día, tras la apertura en 2015 del tramo de autovía Solares-Torrelavega, deja fuera del área funcional parte 
de esta infraestructura y de los municipios recorridos, configurando una delimitación que genera con perspectiva metropolitana más dudas que certezas en este sector sur. Con ello, futuros trabajos podrían orientarse a abordar los planteamientos metodológicos de este artículo para otras unidades funcionales relevantes, como las definidas por Feria y Martínez (2016) que obtuvieron un área funcional en torno a Santander de 32 municipios aplicando avanzadas metodologías de análisis flujos de movilidad.

Así, una profundización en las variables de flujo nos acercaría a una mejor comprensión del área metropolitana de Santander, ya que el aspecto positivo de su grado de madurez, apuntado previamente, llevaría asociada la complejidad del sistema, en cuanto que en ese estadio evolutivo las áreas metropolitanas se comportan como sistemas complejos donde las relaciones territoriales son múltiples y su modelización es fundamental para su adecuada gestión (Aldrey, Pazos, Rodríguez y Vicente, 2010).

Por otro lado, y en relación a la defensa que en este estudio, se hace sobre la incorporación de reveladoras fuentes para el estudio de las áreas metropolitanas, es preciso señalar que aún quedan fuentes de interés por explorar. Entre ellas, contamos actualmente con otras fuentes novedosas, más por el grado de desagregación espacial que por la temática abordada, como son los servicios de Geo-enriquecimiento accesibles a través de la licencia de ArcGIS Pro (ESRI) mediante el servicio Spain AIS-Group. La ventaja fundamental de esta fuente radica en que los datos de variables relativas a población, hogares, renta, gasto, empleo, etc. se calculan y adaptan a las entidades espaciales aportadas por los usuarios (barrios, conjuntos de edificios o digitalizaciones propias de áreas de interés, por ejemplo).

Todo ello podría resultar de interés si las autoridades autonómicas optasen por la creación de un área metropolitana o, al menos, por la coordinación para la cooperación intermunicipal en materia de planeamiento y Agenda Urbana. En cualquier intento de gestión coordinada tiene destacada importancia la superficie, la organización territorial y administrativa e, incluso, la forma del ámbito considerado como área metropolitana, de ahí también el interés que puede tener abordar temáticas como las planteadas en este trabajo. De hecho, en relación con la forma, es importante no basar por defecto los análisis en delimitaciones genéricas a nivel europeo, renunciando a un conocimiento del propio funcionamiento interno del sistema. Así, la interesante clasificación nacional propuesta por Pascual, Aguilera y Salado (2019), donde el área urbana funcional de Santander quedó identificada como un área metropolitana elongada, podría verse modificada si se confirmasen en un futuro alguno de los cuestionamientos hechos en este artículo al límite exterior de la FUA de Santander. Ésta incluye sinuosamente términos municipales hasta configurar un área funcional amplia e irregular que se podría replantear y acotar en base a los criterios analizados y los resultados obtenidos en el presente estudio.

\section{CONCLUSIONES}

La existencia de realidades supramunicipales generadas por los procesos de expansión urbana y metropolitana, y el contexto prioritario de sostenibilidad urbana planteado por la Agenda Urbana, propician un escenario de necesaria reflexión sobre la gobernanza de estos ámbitos y sobre los esfuerzos realizados en materia de planeamiento municipal, cuando los objetivos relativos a la movilidad y a un modelo de crecimiento sostenible sobrepasan claramente las posibilidades de gestión a esa escala administrativa.

Ante tan importante y necesario reto, aún están pendientes de definir criterios únicos para la identificación y delimitación de lo metropolitano en España. Y es en este escenario en el que aparece un nuevo concepto y una nueva zonificación, que se hace ya presente en diversos estudios geográficos sobre la cuestión urbana en nuestro país: las áreas urbanas funcionales. Estos ámbitos se postulan como áreas de interés en cuanto que ponen el foco sobre el dinamismo de ciertas partes del territorio; si bien, es imprescindible dotarlos de contenido y significado, a partir de datos demográficos y del conocimiento de la movilidad diaria y residencial, como vías para perfilar y acotar los municipios que formarían parte definitivamente del área metropolitana de cada unidad funcional.

$Y$ esta es una de las conclusiones que se evidencian en este trabajo, en relación con el estudio específico del área de Santander: área urbana funcional y área metropolitana no tienen un reflejo espacial idéntico y no son conceptos sinónimos. Sus enfoques son solo parcialmente coincidentes. A partir de los resultados del estudio de caso, se observa que el área urbana funcional reconoce una parte del territorio con un claro componente urbano y con movilidad pendular diaria destacada, pero no llega a acotar las relaciones entre unos municipios y otros como base para la delimitación e identificación clara de un área metropolitana.

El aspecto señalado es importante en cuanto que asistimos a un uso creciente de las áreas urbanas 
funcionales en líneas de investigación que años atrás aludían frecuentemente a áreas metropolitanas. Sobre la base del reconocimiento del interés que tiene contar con delimitaciones de áreas urbanas funcionales a nivel europeo, es necesario precisar que su uso puede tener una adecuación variable desde un enfoque multiescalar. Así, en trabajos de ámbito nacional y orientados a alusiones generales sobre los territorios de rasgos urbanos, la fuente contaría con elevado potencial. Sin embargo, para analizar un estudio de caso, o a escalas regionales, o incluso en iniciativas concretas de delimitación de áreas metropolitanas en clave de gobernanza, su papel puede quedar relegado a área envolvente de referencia, a modo de ventana o marco de interés, para identificar y concretar la realidad metropolitana combinando otros rasgos, como los aquí planteados.

Con un enfoque similar al expuesto, la consideración de los límites de las áreas urbanas funcionales y el análisis del comportamiento de la población en ese territorio permitirían abordar estudios de forma y dimensión más ajustados sobre la configuración de las áreas metropolitanas en España. En este sentido, las fuentes incorporadas en el presente estudio y los métodos de análisis serían extrapolables a otros sistemas tanto españoles como del resto de Europa, con las adaptaciones oportunas. En suma, queda abierto un espacio para la reflexión. Parece que es un momento propicio para retomar la importancia de la coordinación intermunicipal en el marco de la Agenda Urbana para aquellos objetivos que impliquen actuar sobre flujos y vectores (movilidad diaria especialmente), así como sobre procesos que afectan a la sostenibilidad. En relación con esto último, parece que solo con trabajo coordinado intermunicipal será posible evitar la fragmentación y el crecimiento disperso, garantizando una infraestructura verde que adecúe las ratios de suelo no artificial por habitante con perspectiva multiescalar.

En este contexto, el papel de las administraciones autonómicas es fundamental para iniciar el diálogo con los ayuntamientos protagonistas de la cuestión metropolitana. Las vías de colaboración y coordinación son múltiples, como lo es también la dimensión y la expresión espacial de lo metropolitano. Las oportunidades de entendimiento supramunicipal irían desde colaboraciones sectoriales hasta un tratamiento más formal y reconocido institucionalmente a través de las leyes de creación de áreas metropolitanas, como es el caso de Barcelona y Vigo, y previsiblemente podría serlo también Valencia en un futuro no lejano.

\section{REFERENCIAS BIBLIOGRÁFICAS}

Aldrey, J. A., Pazos, M., Rodríguez, R. y Vicente, J. (2010). Caracterización de las áreas urbanas gallegas en función de los flujos de movilidad obligada. Cuadernos de Geografía, 88, 219-234. Recuperado de https://ojs.uv.es/index.php/CGUV/article/ view/14263

Artmann, M., Inostroza, L. y Fan, P. (2019). Urban sprawl, compact urban development and green cities. How much do we know, how much do we agree? Ecological Indicators 96, 3-9. doi: https:// doi.org/10.1016/j.ecolind.2018.10.059

Bibri, S. E., Krogstie, J. y Kärrholm, M. (2020). Compact city planning and development: Emerging practices and strategies for achieving the goals of sustainability. Developments in the Built Envirnoment, 4(100021). doi: https://doi.org/10.1016/j. dibe.2020.100021

CEC, Comisión de las Comunidades Europeas (1990). Libro verde sobre el medio ambiente urbano. Comunicación de la Comisión al Consejo y al Parlamento. Bruselas. Recuperado de https://tinyurl. com/3w2yrrtp

Checa, J., Martín, J., López, J. y Nel•lo, O. (2020). Los que no pueden quedarse en casa: movilidad urbana y vulnerabilidad territorial en el área metropolitana de Barcelona durante la pandemia COVID-19. Boletín de la Asociación de Geógrafos Españoles, 87. doi: https://doi.org/10.21138/bage.2999

Corbane, C., Florczyk, A., Pesaresi, M., Politis, P. y Syrris, V. (2018). GHS built-up grid, derived from Landsat, multitemporal (1975-1990-2000-2014), R2018A. European Commission, Joint Research Centre (JRC). doi: 10.2905/jrc-ghsl-10007 PID: http://data.europa.eu/89h/jrc-ghsl-10007

De Cos, O. (2004). Valoración del método de densidades focales (kernel) para la identificación de los patrones espaciales de crecimiento de la población en España. Geofocus, 4, 136-165.

De Cos, O. (2005). Propuesta de delimitación del área metropolitana de Santander. Realidad funcional, organización administrativa y gobernanza. Santander, España: Gobierno de Cantabria, Centro de Estudios de la Administración Regional de Cantabria (CEARC).

De Cos, O. (2020). Dispersión y artificialización de las áreas urbanas funcionales españolas. Propuesta tipológica basada en el programa europeo Coper- 
nicus. Ciudad y Territorio. Estudios Territoriales, 52(205), 477-492. doi: https://doi.org/10.37230/ CYTET.2020.205.03

De Cos, O. y De Meer, A. (2013). Las áreas metropolitanas de tamaño medio. La configuración de un espacio de cohesión en el conjunto polinuclear Santander-Torrelavega. Ciudad y Territorio. Estudios Territoriales, 45(176), 351-362. Recuperado de https://recyt.fecyt.es/index.php/CyTET/article/view/76211

De la Cruz, A. (2019). La Agenda Urbana Española. Ciudad y Territorio. Estudios Territoriales, 51(202), 675-686. https://recyt.fecyt.es/index.php/CyTET/ article/view/77728/49325

De Oliveira, G. (2018). El espacio urbano metropolitano español en el cambio de siglo. Ciudad y Territorio. Estudios Territoriales, 50(198), 769-786. Recuperado de https://recyt.fecyt.es/index.php/ CyTET/article/view/76699

Dijkstra, L. y Poelman, H. (2012): Cities in Europe. The new OECD-EC definition (Regional Focus 1/2012). Recuperado de https://tinyurl.com/y5ubz4kg

Feria, J. M. (2020). Los procesos metropolitanos en España. Intensificación estructural y nuevos desafíos. Papers, 61, 28-40.

Feria, J. M. y Martínez, L. (2016). La definición y delimitación del sistema metropolitano español: permanencias y cambios entre 2001 y 2011. Ciudad y Territorio. Estudios Territoriales, 48(187), 9-24. Recuperado de https://recyt.fecyt.es/index.php/ CyTET/article/view/76461

Feria, J. M. y Santiago, J. (2019). Landscape Spatial Analysis for Sustainable Land Use Planning: A TwoScale Approach to the Seville Metropolitan Area. Journal of Planning Education and Research, 1-14. doi: https://doi.org/10.1177/0739456X19845439

Fernández-Milán, B. y Creutzig, F. (2016). Municipal policies accelerated urban sprawl and public debts in Spain. Land Use Policy, 54, 103-115. doi: https:// doi.org/10.1016/j.landusepol.2016.01.009

Frank, S., Spyra, M. y Fürst, C. (2017). Requirements for cross-border spatial planning technologies in the European context. Change Adaptation Socioecological Systems, 3, 39-46. Recuperado de https://tinyurl.com/6m85tev5

García-Palomares, J. C. y Pozo, E. (2010). Movimientos migratorios en la Comunidad de Madrid: unos flujos más intensos y complejos (1991-2006). Boletín de la Asociación de Geógrafos Españoles, 53, 89119. Recuperado de https://www.age-geografia. es/ojs/index.php/bage/article/view/1194/1117

GMES, Global Monitoring for Enviroment and Security. (2017). Initial Operations. Copernicus Land monitoring services - Validation of products. Recuperado de https://land.copernicus.eu/user-corner/ technical-library/ua-2012-validation-report

Gómez, J. M., Sá Marques, T. y Hernández, A. (2020). Procesos urbanos y funcionales en Iberia. Cuadernos Geográficos 59(2), 93-128. Recuperado de https://tinyurl.com/rm3jrc2e

González-Medina, M., Huete, M. A. y Merino, R. (2016). La evolución de la agenda urbana de la Unión Europea: Hacia un modelo de desarrollo urbano sostenible integrado. WPS Review International on Sustainable Housing and Urban Renewal, 1(4), 83-95. Recuperado de https://bit. ly/3gzxTUW

Guastella, G., Oueslati, W. y Pareglio, S. (2019). Patterns of Urban Spatial Expansion in European Cities. Sustainability, 11(2247). doi: https://doi. org/10.3390/su11082247

Hildenbrand, A. (2017). El abandono de la cuestión metropolitana en España. RiURB Revista lberoamericana de Urbanismo, 13, 25-46. Recuperado de http://hdl.handle.net/2117/108615

Lobato-Becerra, J. A. (2020). Notas sobre la obsolescencia de los planes generales: planificación estratégica y modelo urbano. Ciudad y Territorio. Estudios Territoriales, 52(204), 197-210. doi: https://doi.org/10.37230/CyTET.2020.204.01

López-Gay, A. (2011). ¿Vuelve el centro? Caracterización demográfica de los procesos de reurbanización en las metrópolis españolas. En I. Pujadas, et. al. (Ed). Población y espacios urbanos. Actas del XII Congreso de la Población Española (pp. 163-180). Barcelona, España. Universitat de Barcelona.

López-Gay, A. (2016). El advenimiento de las regiones metropolitanas maduras en España: retos demográficos y socioeconómicos en un nuevo contexto urbano. Panorama Social, 23, 179-196. Recuperado de https://tinyurl.com/ysnej2y9

Martí, M. y Ródenas, C. (2006). Reinterpretando el crecimiento de la movilidad en España: la población extranjera y las migraciones repetidas. Cuadernos aragoneses de economía, 16(1), 37-60. Recuperado de https://tinyurl.com/rsrn733d 
Marmolejo, C., Ruiz, N. y Tornés, M. (2015). ¿Cuán policéntricas son nuestras ciudades? Un análisis para las siete grandes áreas metropolitanas en España. Ciudad y Territorio. Estudios Territoriales, Vol. 47(186), 679-700. Recuperado de https://recyt.fecyt.es/index.php/CyTET/article/ view/76439/46786

Melchiorri, M., Florczyk, A. J., Freire, S., Schiavina, M., Pesaresi, M. y Kemper, T. (2018). Unveiling 25 years of planetary urbanization with remote sensing: perspectives from the Global Human Settlement Layer. Remote Sensing, 10(768). doi: https://doi.org/10.3390/rs10050768

Münter, A. y Volgmann, K. (2020). Polycentric regions: Proposals for a new typology and terminology. Urban Studies, 58(4), 677-695. doi: https://doi. org/10.1177/0042098020931695

Naciones Unidas (2018). The World's Cities in 2018. World Population Prospects. The 2018 Revision. Department of Economic and Social Affairs, Population Division. Recuperado de https://population.un.org/wup/Publications/Files/WUP2018Report.pdf

Olazabal, E. y Bellet, C. (2016). Urbanización extensa en los entornos de ciudades medias españolas. En: B. Ruiz-Apilánez \& E. Solís \& V. Romero de Ávial, (Coords.): Forma urbana. Pasado, presente y perspectivas. Actas del I Congreso Hispanic International Seminar on Urban Form (pp. 161170). Universidad de Castilla-La Mancha. Recuperado de https://tinyurl.com/3jxep8rd

Olazabal, E. y Bellet, C. (2019). De la ciudad compacta a la ciudad extensa. Procesos de urbanización recientes en áreas urbanas españolas articuladas por ciudades medias. Anales de Geografía de la Universidad Complutense, 39(1), 149-175. doi: https://doi.org/10.5209/aguc.64681
Oliveras, J. y Cartanyà, A. (2015). Ciudades difusas y confusas, conurbaciones y áreas metropolitanas. El caso del Camp de Tarragona. International Conference on Regional Science: innovation and geographical spillovers. AECR, p. 1526. Recuperado de https://old.reunionesdeestudiosregionales. org/Reus2015/htdocs/pdf/p1526.pdf

Pascual, V., Aguilera, F. y Salado, M. J. (2019). Clasificación y análisis de los procesos de cambio en la forma urbana de las áreas metropolitanas españolas: aplicación de métricas espaciales. Estudios geográficos, 80(286). doi: https://doi. org/10.3989/estgeogr.201926.006

Pesci, R. (2018). Stepping stones, nuevo paradigma de territorio y urbanización: la ciudad desde fuera. Ciudad y Territorio. Estudios Territoriales, 40(195), 21-32. Recuperado de https://apps.fomento.gob. es/CVP/handlers/pdfhandler.ashx?idpub=BP1023

Selva-Royo, J. R. (2020). La cuantificación metropolitana en España. Hacia una definición homogénea de los espacios de gobernanza supramunicipal. Ciudad y Territorio. Estudios Territoriales, 52(204), 211-228. doi: https://doi.org/10.37230/ CYTET.2020.204.02

Susino, J. (2011): “La evolución de las migraciones interiores en España: una evaluación de las fuentes demográficas disponibles". Papers, 96(3), 853-881.

Treviño, R. y Domingo, A. (2020). ¿Adiós al censo en España? Elementos para el debate. Revista Española de Investigaciones Sociológicas, 171, 107-124. doi: http://dx.doi.org/10.5477/cis/reis.171.107

Zornoza, C. (2019). Pautas de movilidad e impacto de la dispersión urbana: análisis de la provincia de Valencia a partir de nuevas fuentes de datos. Boletín de la Asociación de Geógrafos Españoles, 82(2773), 1-26. doi: http://dx.doi.org/10.21138/bage.2773 